تأثير رزيمهاى مختلف آبيارى بر صفات رويشى و زايشى زنوتيّهاى برنج هوازى در شمال خوزستان

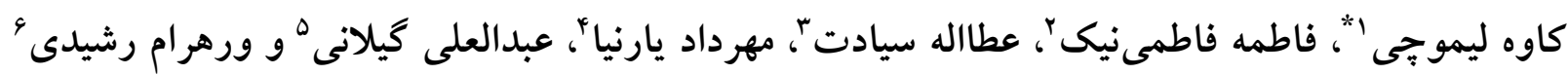

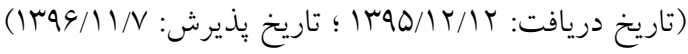

צكيده

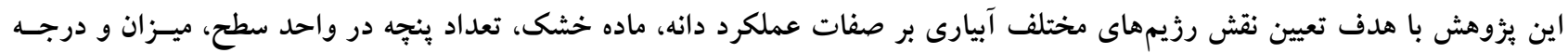

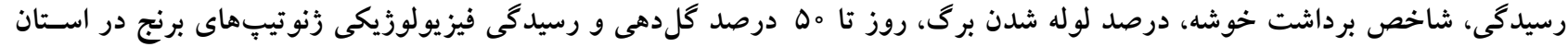

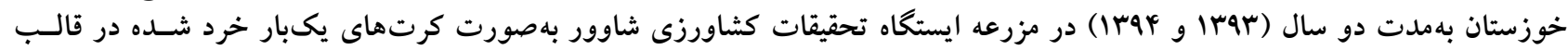

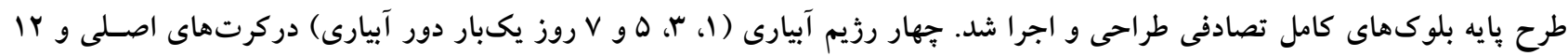

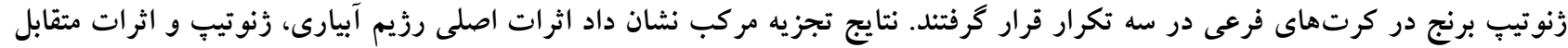

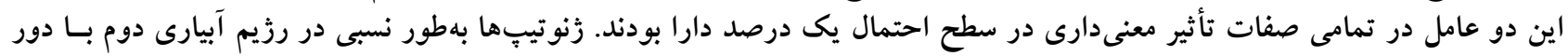

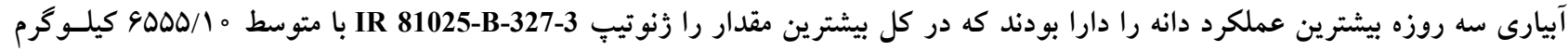

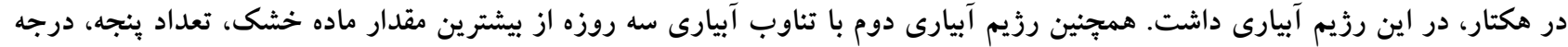

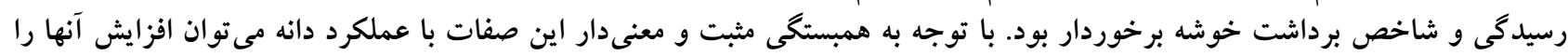

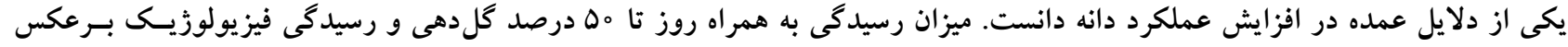

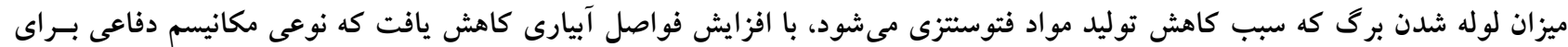
فرار از خشكى است.

وازمهاى كليدى: فواصل آبيارى، عملكرد، بيولوزيك، ينجه، رسيدگى

ا. دكتراى زراعت، باشكاه يُزوهشكران جوان و نخبحان، واحد دزفول، دانشَاه آزاد اسلامى، دزفول، ايران r. مربى، كروه كشاورزى، دانشخاه بيام نور ايران r. استاد، كروه زراعت، دانشخاه كشاورزى و منابع طبيعى رامين

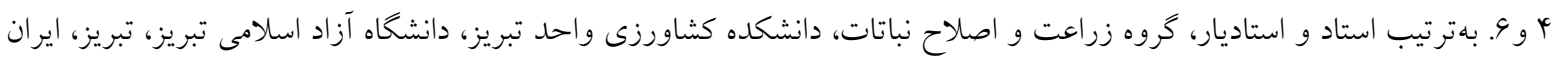

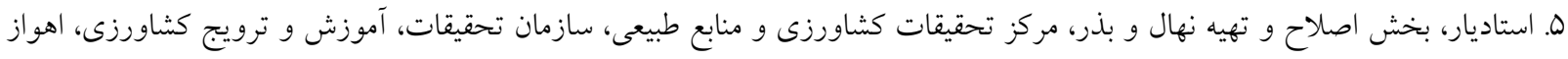

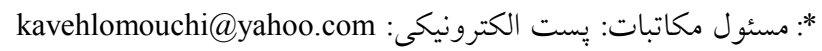


شوشى دزفولى افزايش تعداد دانسه در خوشـه و همجنـين افزايش

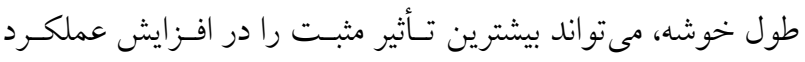

دانه برنج داشته باشد (ب9).

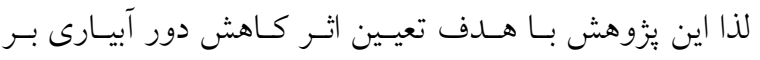

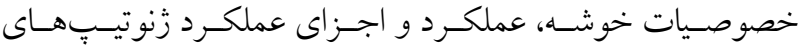
مختلف برنج جهت شـناخت و بـهــاركيرى سـازو كار مناسـب در برنامهاى اصلاحى به اجرا كذاشته شد.

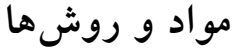

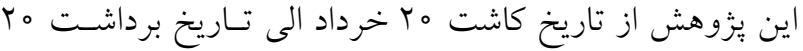

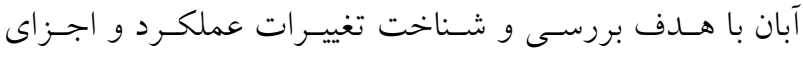

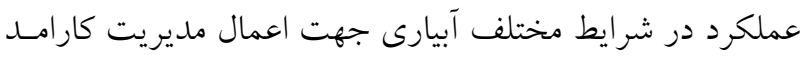

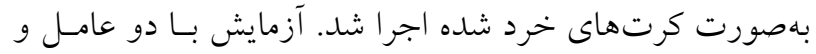

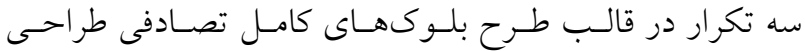
كَرديد. كشت به روش خشكهارى در كرتهاى اصلى

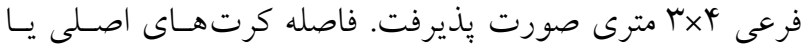
تكرارها از يكديخر، جهـار متـر و فاصـله كـرتهـاى فرعى از

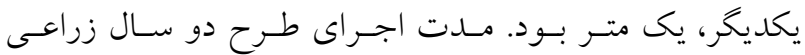

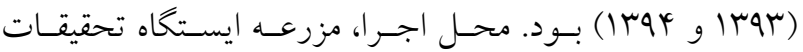
كشاورزى شاوور وابسته به مركز تحقيقـات كشـاورزى و منـابع طبيعى ايران در استان خوزستان در \& Vيلومترى شـمال اهـواز حدفاصل دو رودخانه كرخه و كارون بود. منطقه مورد كشت در

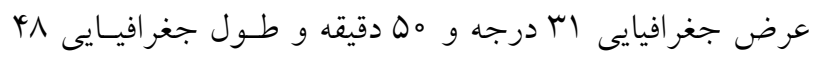

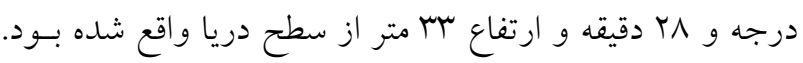

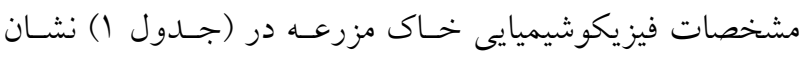
داده شده است. جهار رزيم آبيارى شامل تناوبهـاى يـك روزه

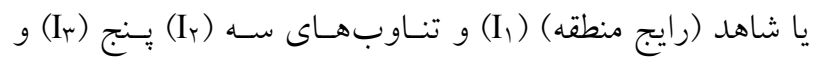

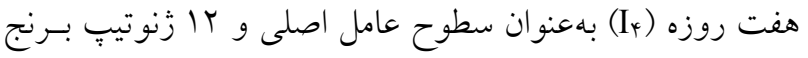

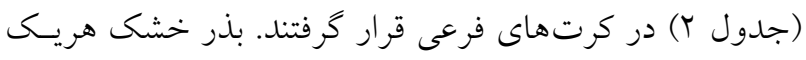

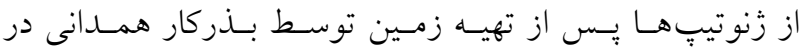

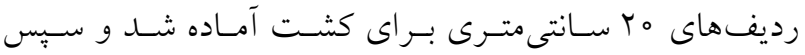

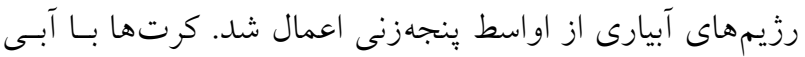

برنج يكى از قديمى ترين گياهان زراعى است (T) (I). برنج بـهنـوان

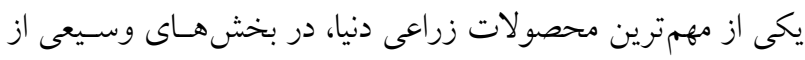

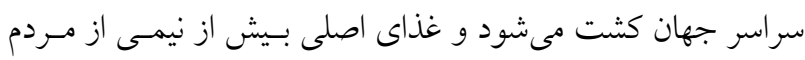

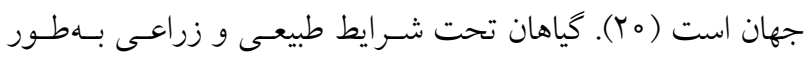
بيوسته در معرض تنشهاى گونـاكون قـرار دارنــــ و در ايـن ميـان

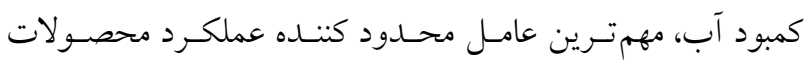

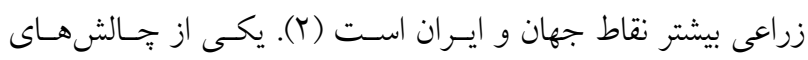

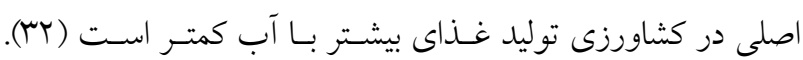

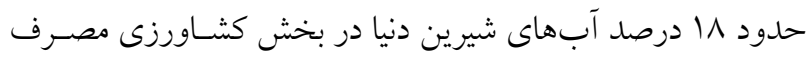

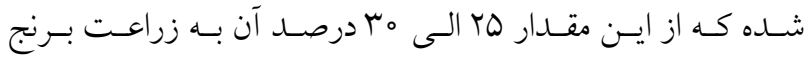

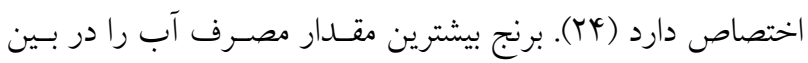

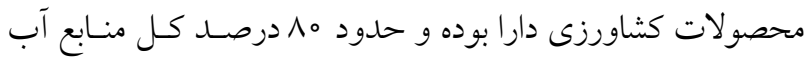

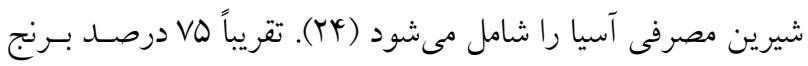

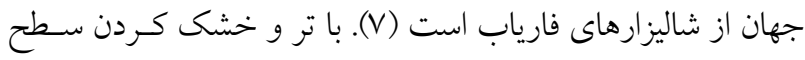
خاك مزرعه از طريـق آبيـارى متنـاوب، تبـادل هـوا بـين خهاك و اتمسفر برقرار شده (آس) در آبيارىهاى تهند روز يك بـار اكسيزن

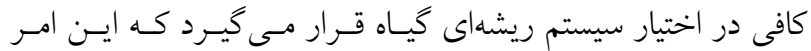
موجب سرعت بخشيدن به معلى شدن مواد آلى و تثبيت نيتـروزن

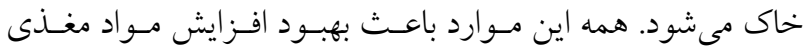

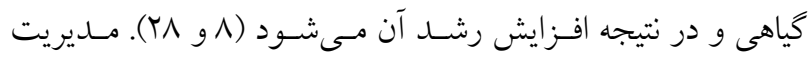

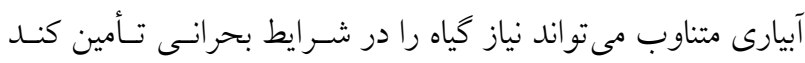

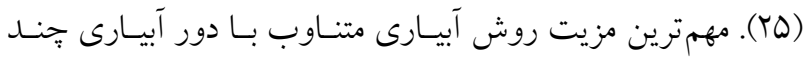

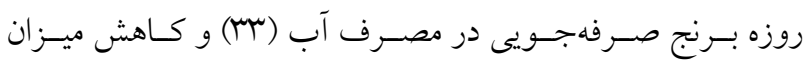

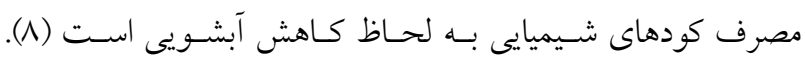

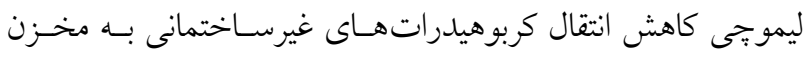

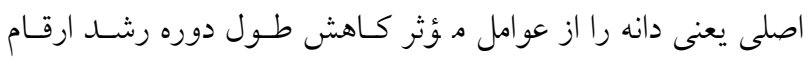

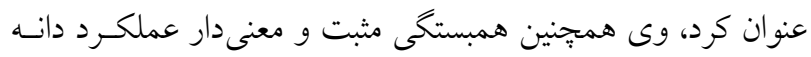

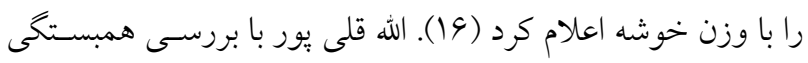

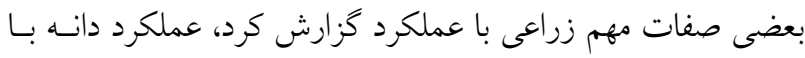

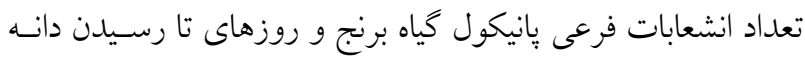

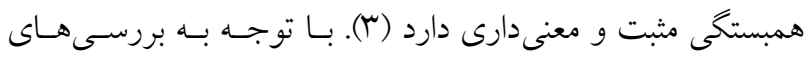


جدول ا. ويزَى هاى خاك مزرعه تحقيقاتى

\begin{tabular}{|c|c|c|c|c|c|c|c|c|c|c|}
\hline \multirow{2}{*}{ بافت خاى } & $\mathrm{Fe}$ & $\mathrm{Mn}$ & $\mathrm{Zn}$ & $\mathrm{Cu}$ & $\mathrm{K}$ & $\mathrm{P}$ & \multirow{2}{*}{$\begin{array}{c}\mathrm{N} \\
(\%)\end{array}$} & \multirow{2}{*}{$\begin{array}{c}\mathrm{EC} \\
(\mathrm{dS} / \mathrm{m})\end{array}$} & \multirow{2}{*}{$\mathrm{pH}$} & \multirow{2}{*}{ 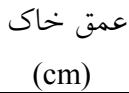 } \\
\hline & \multicolumn{6}{|c|}{ (ppm) } & & & & \\
\hline رسى -لومى & $10 / Y$ & $r / \omega$ & $r / D$ & $r / 1$ & rrI & 11 & $0 / 09$ & $r / \Delta$ & $\mathrm{V} / \mu$ & $r_{0-0}$ \\
\hline
\end{tabular}

\begin{tabular}{|c|c|c|c|c|}
\hline تحمل به خشكى & 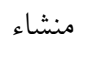 & 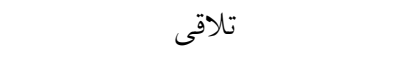 & ز زنوتيب & \\
\hline 1 & 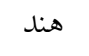 & C 22/KALAKERI & VANDANA & $\mathrm{V}_{1}$ \\
\hline 1 & 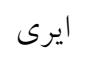 & VANDANA/IR 65 & IR 78908-193-B-3-B & $\mathrm{V}_{r}$ \\
\hline 1 & 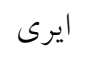 & IR 78908-44/IR 78908-86 & IR $81429-B-31$ & $\mathrm{~V}_{r}$ \\
\hline r & 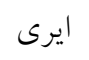 & PSB RC 9/IR 64 & IR 78875-176-B-1-B & $\mathrm{V}_{*}$ \\
\hline 0 & 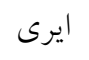 & VANDANA/WAYRAREM & IR 79971-B-202-2-4 & $\mathrm{V}_{\Delta}$ \\
\hline v & ايرى اير & PSB RC 9/AUS 257 & IR 80508-B-194-4-B & $\mathrm{V}_{4}$ \\
\hline 0 & ايرى اير & PSB RC 9/AUS 257 & IR 80508-B-194-3-B & $\mathrm{V}_{\mathrm{v}}$ \\
\hline 0 & 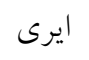 & IR 55419-04/IR 64 & IR 79907-B-493-3-1 & $\mathrm{V}_{\wedge}$ \\
\hline 0 & ايرى ائ & NSIC RC 140/IR 74371-3-1-1 & IR $81025-B-347-3$ & $\mathrm{~V}_{\mathrm{a}}$ \\
\hline r & 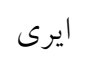 & NSIC RC 140/IR 74371-3-1-1 & IR 81025-B-327-3 & $V_{1}$ 。 \\
\hline r & 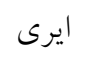 & SANG TARAM/AMOL 3 & ندا & $\mathrm{V}_{11}$ \\
\hline 9 & ايرى اي & - & 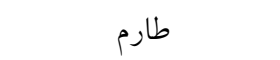 & $V_{i r}$ \\
\hline
\end{tabular}

هو اشناسى در (جدول r) آورده شده است. براى تـأمين عناصـر

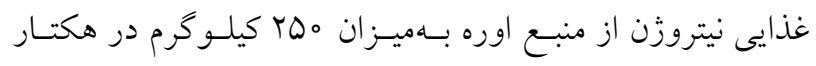

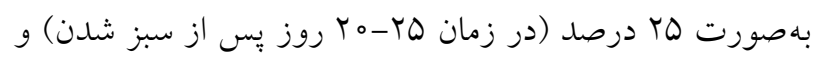

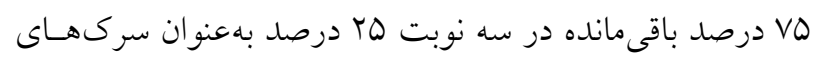

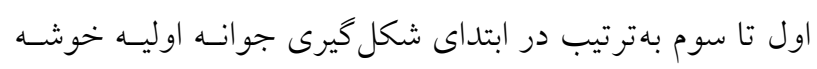

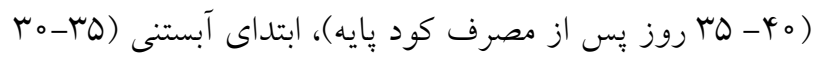

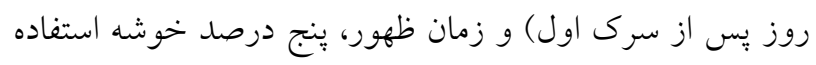

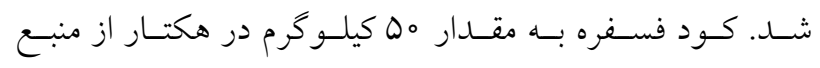

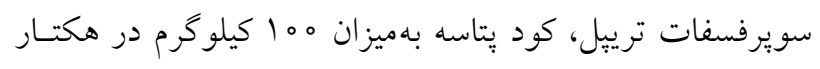

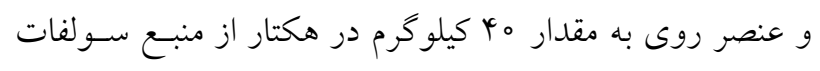

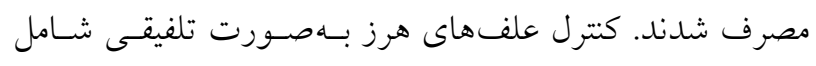

كه توسط ِمٍٍ تأمين و كتترل مىشود تا ارتفاع بنج سـانتىمتر

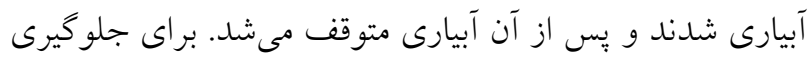

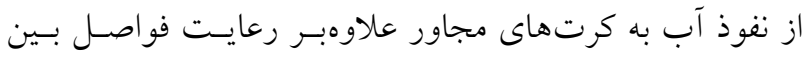

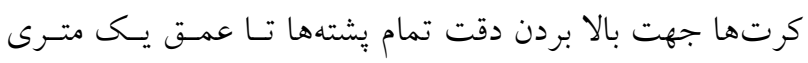

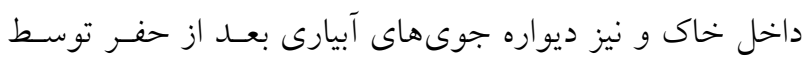

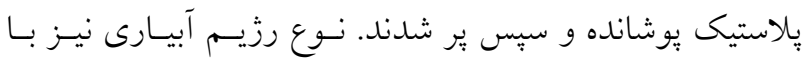

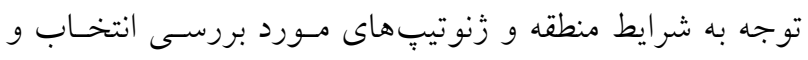

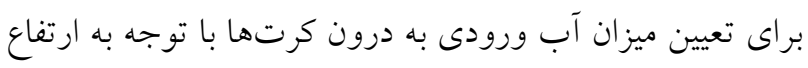

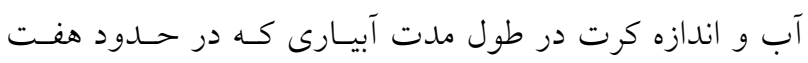

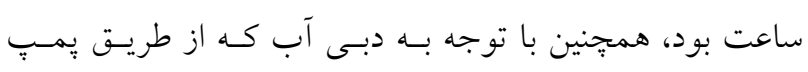

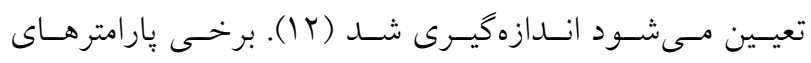


جدول r. ميانگين حداقل و حداكثر دماى ماهيانه (كاشت تا برداشت) طى سالهاى زراعى

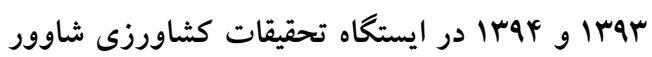

\begin{tabular}{|c|c|c|c|c|}
\hline \multicolumn{2}{|c|}{$(1+q 4)$} & \multicolumn{2}{|c|}{$(1$ (1 } & سال \\
\hline ميانخين حداكثر & ميانگين حداقل & ميانكين حداكثر & ميانكين حداقل & \multirow{2}{*}{ ماه } \\
\hline \multicolumn{4}{|c|}{ (درجه سانتى گراد) } & \\
\hline $49 / T$ & $r q / 9$ & ky & rq & خرداد \\
\hline$r \Delta / V$ & $T V / \Lambda$ & $\forall \& / N$ & $T V / \Lambda$ & تير \\
\hline$\& \mathrm{~V} / \mathrm{Q}$ & $r q / 1$ & $\$ 4 / 0$ & $T V / \Lambda$ & مرداد \\
\hline$k+/ 9$ & $T V / 4$ & $\mu \varphi / 0$ & $r \Delta / r$ & شهريور \\
\hline$r q / 0$ & $T Y / T$ & rی & rI & مهر \\
\hline TV/A & $10 / 1$ & rq & $I T N$ & آبان \\
\hline$F 1 / M$ & TY/AT & $41 / 40$ & $r M / 4 T$ & ميانخين \\
\hline
\end{tabular}

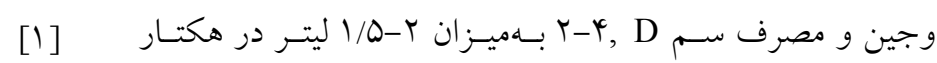

بيشترين عرض بهنك برى درحالت

$$
\begin{aligned}
& \text { 100 }
\end{aligned}
$$

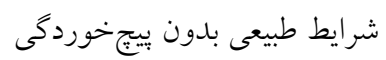

كليه دادهاى حاصل از آزمايش با استفاده از نرمافزارهاى آمارى

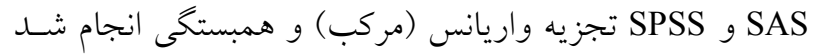

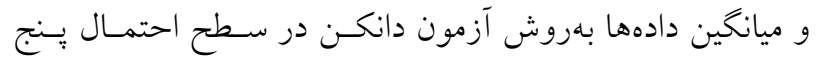

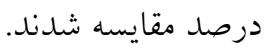

\section{نتايج و بحث

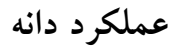

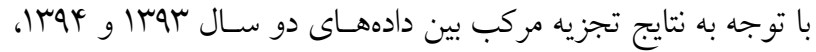

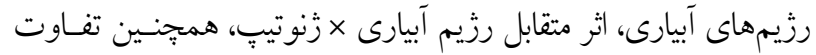

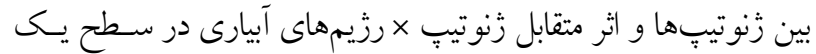

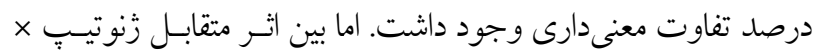

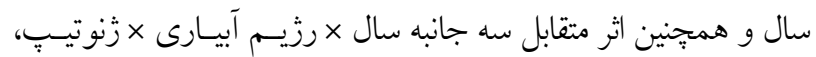

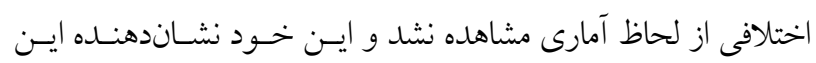

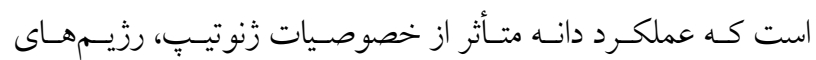
مختلف آبيارى و برآيند همخر ايى مثبت آنها است، يـا در واقـع تـأثير

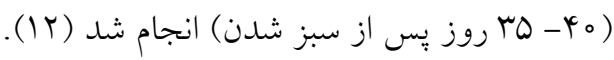

با رسيدن هم درصد دانهها در خوشه با بررسى خوشهههـاى

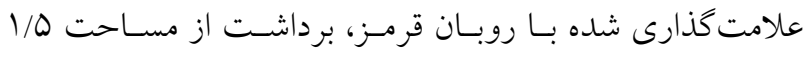

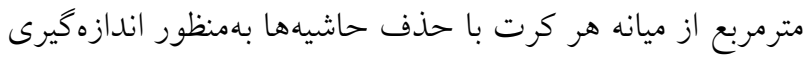

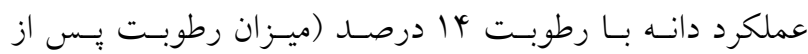

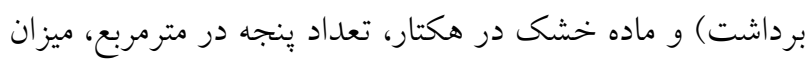

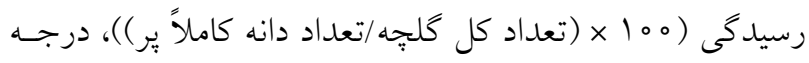

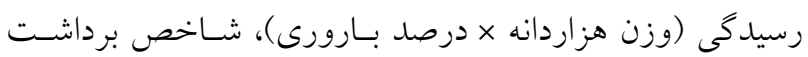

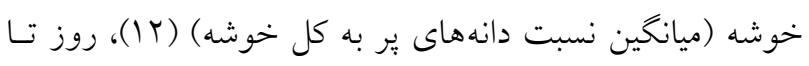

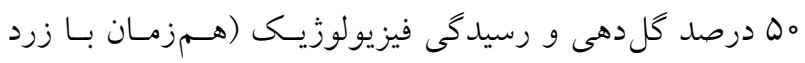

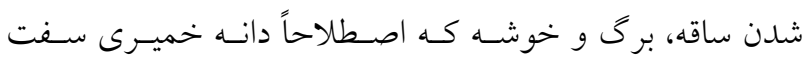

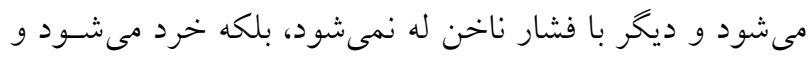

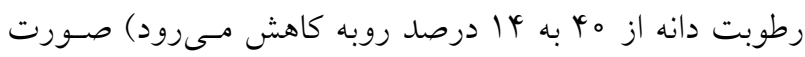

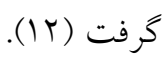
در مرحله ظهور خوشه، ميـانخين درصــ لولـه شــدن بـرى

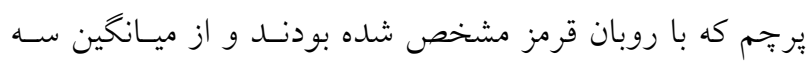
تكرار در هر كرت با استفاده از خطكش ميلى مترى در مزرعه از طريق رابطه (1) محاسبه شد (بr): 


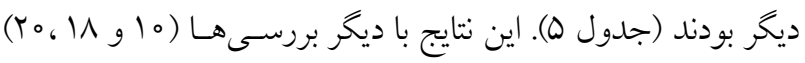

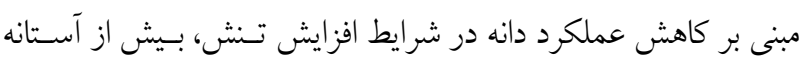

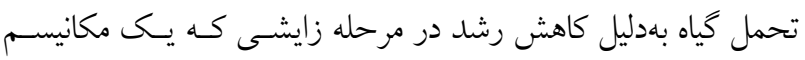

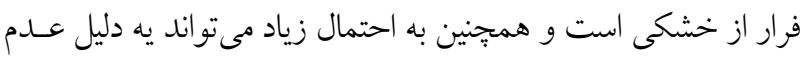
انتقال و تخصيص كربوهيدارتها و قندها به دانه باثد، مطابقـت دارد.

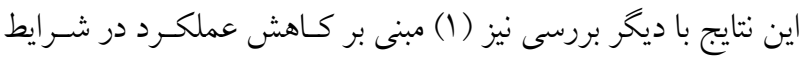

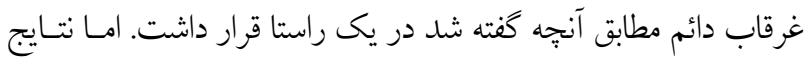
بهدست آمده با بررسى قاسمى و همكاران كه اظهـار كردنــد افـزيش

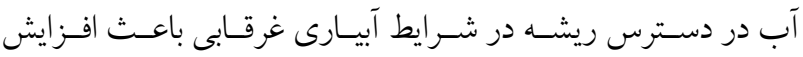
عملكرد برنج مىشود، مغايرت دارد (11).

\section{ماده خشك در هكتار}

نتايج اين بررسى نشان داد در بين كليه سطوح مورد بررسى به غيـر

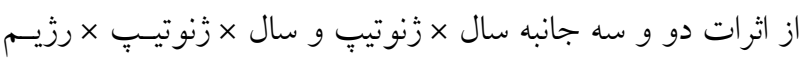

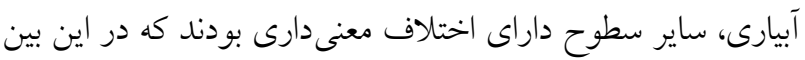

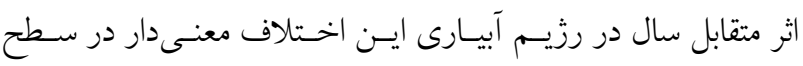

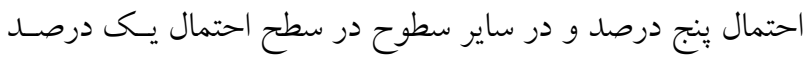

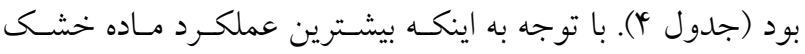

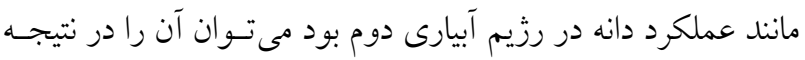

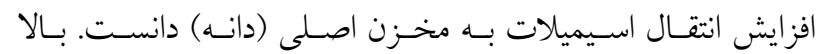

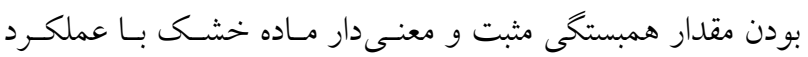

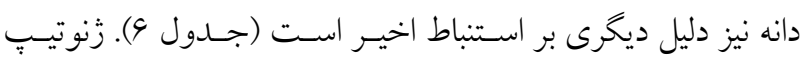

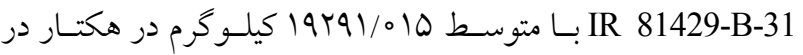
رزيم آبيـارى سـه روزه، بيشـترين عملكــــ بيولوزيــ را دارا بـود.

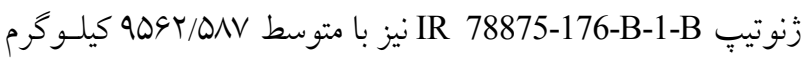

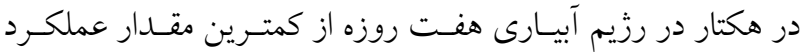
بيولوزيك برخوردار بود (جــول ه). نتـايج كذشـته از توضسيحات داده شده در عملكرد دانه مى تواند بـه علـت اختلافـات زنــوتيبى و

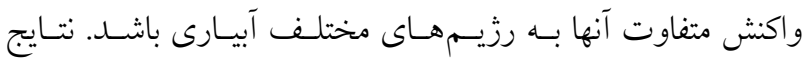

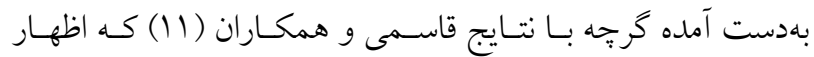
كردند آبيارى غرقاب سبب افزايش ماده خشك مسى شــود مغـايرت

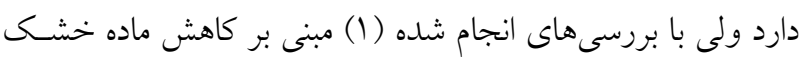

آنها برروى صفت مزبور به يك نسبت است و افزايش يا كـاهش هـر

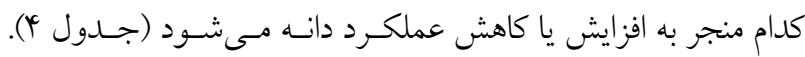

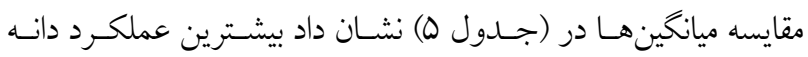

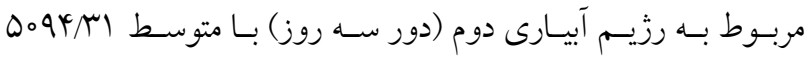

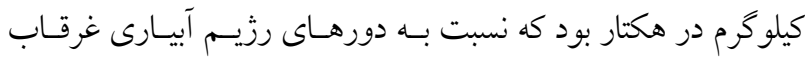

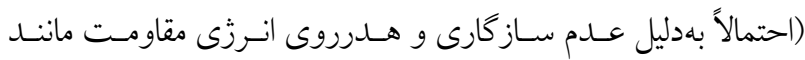

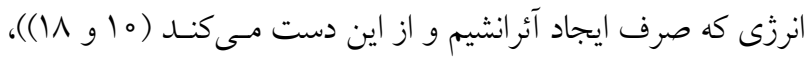

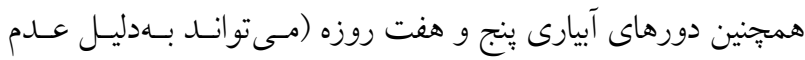
تسهيل در دسترسى به مواد غذايى و تجمـع اسـيميلاتهــا در قاعـــه

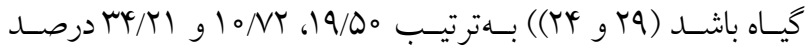

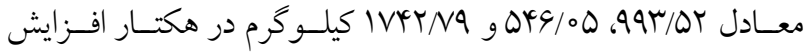

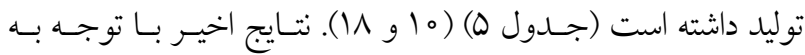

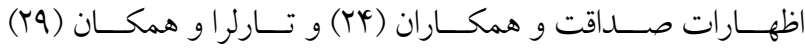
نشاندهنده اين است كه در صورت مهيا بودن شـــايط آبيـارى، رزيـم

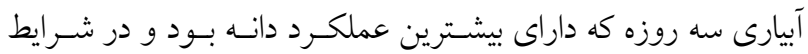

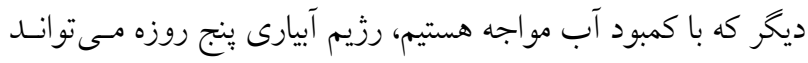

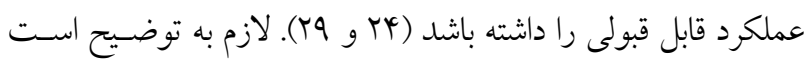

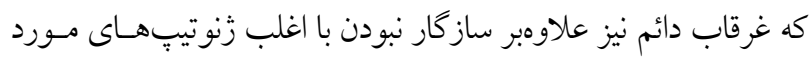

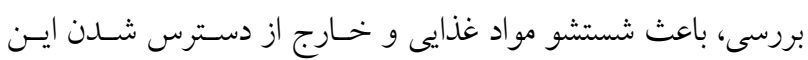

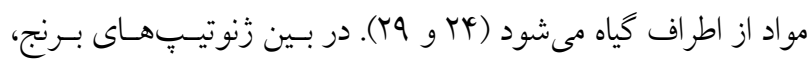
زنوتيب IR 81025-B-327-3 بر سايرين برترى داشــت كـه بيشـترين

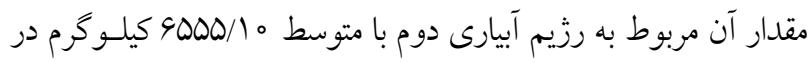

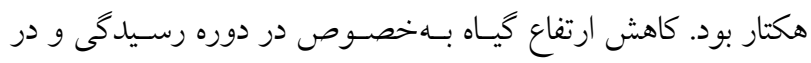
نتيجـه تخصسيص كربوهيــارت بيشـتر بـه مقصــ اصسلى از دلايـل سازكارى و برترى اين زنوتيب است (جدول ه)، همجنين اثر متقابـل

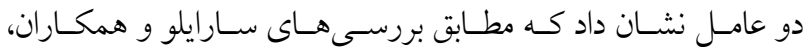

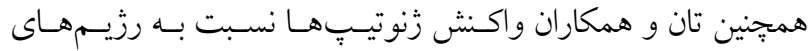
مختلف آبيارى متفاوت بود (TV و TV). به كونهاى كه تمام زنوتيبهـا در رزيم آبيارى جهارم بهدليل كـاهش طـول دوره رشــ و در نتيجـه تخصيص كمتر كربوهيدراتها به مخزن اصـلى و در نهايـت كـاهش

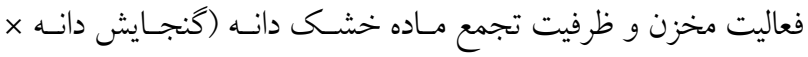
تعلاد دانه) داراى كمترين عملكرد دانه نسبت بـه رزيـمهــاى آييـارى 


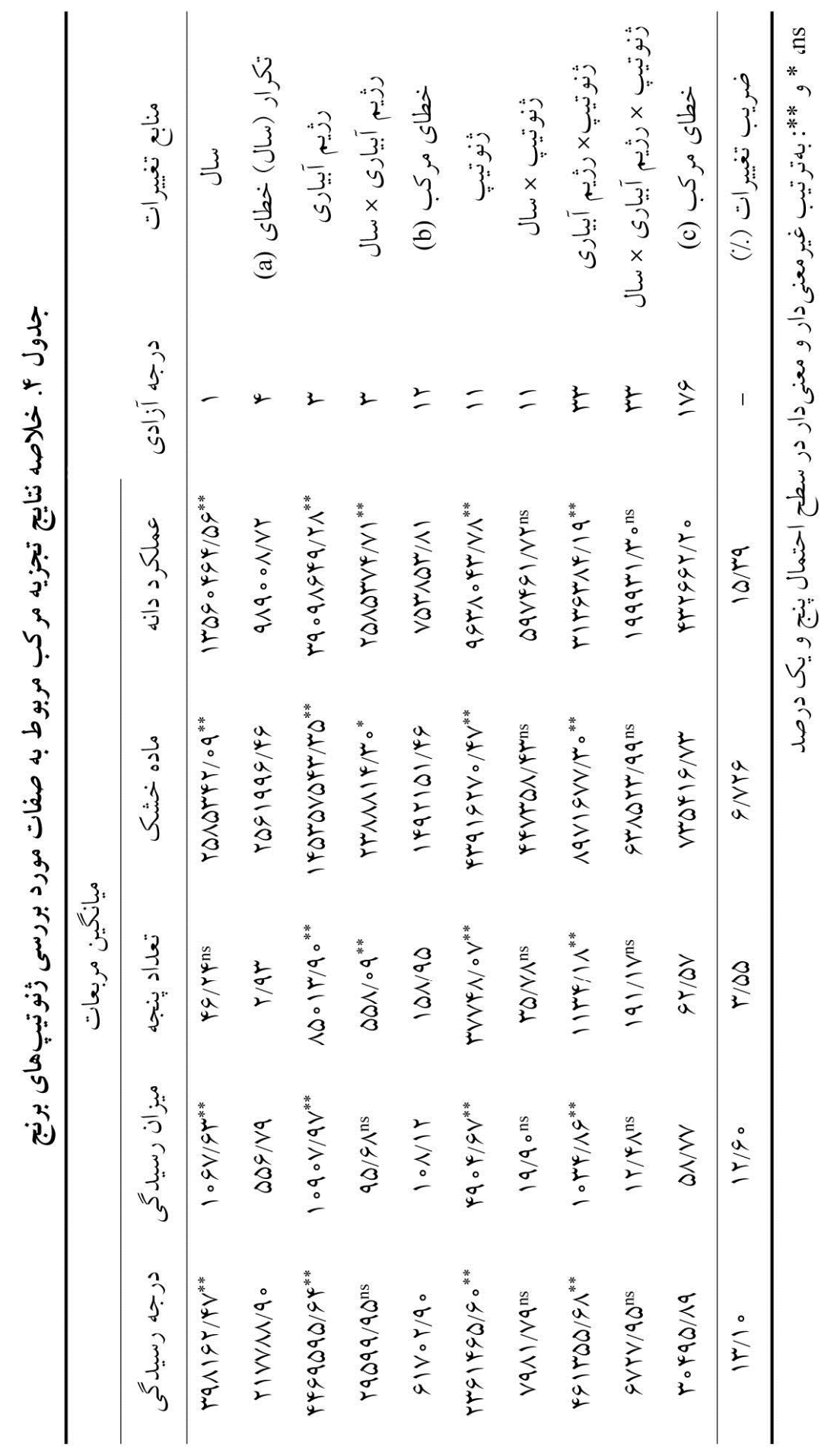




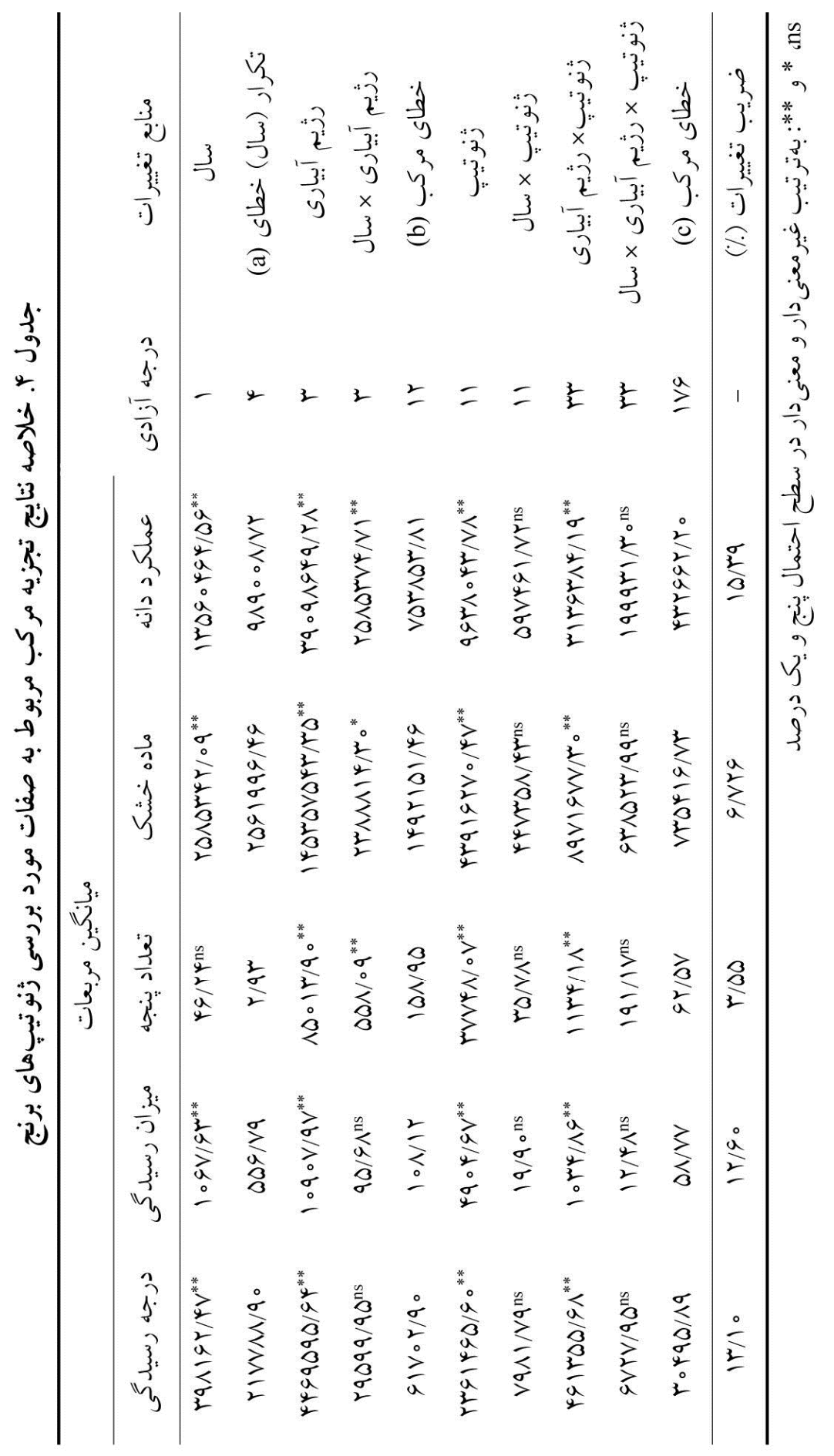


جدول ه. نتايج مقايسه ميانخين دو ساله مربوط به صفات مورد بررسى زنوتيبّهاى برنج در تيمارهاى آزمايشى

\begin{tabular}{|c|c|c|c|c|c|c|}
\hline \multirow{2}{*}{ رسيدگى } & \multirow{2}{*}{ ميزان رسيدگى (درصد) } & \multirow{2}{*}{ تعداد ينجهة } & \multirow{2}{*}{ 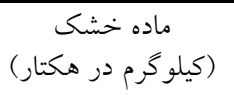 } & \multirow{2}{*}{ 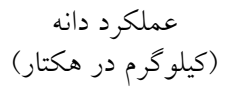 } & \multicolumn{2}{|c|}{ تيمار } \\
\hline & & & & & زَنوتيِ & رزيم آبيارى \\
\hline $1<r b^{h-k}$ & $9^{\mathrm{ffh}^{\mathrm{fh}}}$ & $1 \Lambda Y^{p-r}$ & $1 \circ \Delta 4 \Delta^{p-u}$ & TMTYxy & VI & \\
\hline $1 \vee q^{b-d}$ & $\Lambda^{\mathrm{a}-\mathrm{d}}$ & r/A de & $104 \cdot 0^{b c}$ & $r \circ \mu \Lambda^{j-t}$ & Vr & \\
\hline $10 V q^{\mathrm{d}-\mathrm{i}}$ & $n^{\mathrm{d}-\mathrm{f}}$ & $r \wedge I^{e}$ & $1 Q \Delta<q^{b c}$ & $\left.Y \Delta \Delta\right|^{d-n}$ & $\mathrm{Vr}$ & \\
\hline $10 \wedge \mu^{d-i}$ & $99^{\text {ef }}$ & rrqa & IrVGqe-h & rqpqu-x & $V^{4}$ & \\
\hline $194 r^{a b}$ & $\Lambda^{k a-c}$ & $r \Delta \Delta^{g}$ & 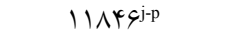 & $r \Delta \& 1^{0-w}$ & Vo & $c$ \\
\hline $194 d^{d-h}$ & $V \varphi^{c-e}$ & $r \Delta \psi^{r g}$ & $|r \Delta| \mathrm{A}^{\mathrm{i}-1}$ & $\mu \psi \wedge V^{f-p}$ & V4 & $n$ \\
\hline $10 r \Delta^{e-j}$ & $99^{\mathrm{ef}}$ & r|flm & $11 \Delta \Delta \lambda^{\mathrm{k}-\mathrm{r}}$ & $r \Delta \Delta q^{n-w}$ & Vv & $\Sigma_{1}$ \\
\hline$\Lambda \circ r^{o-r}$ & $r a^{k l}$ & $r \circ r^{n}$ & $11011^{\text {cot }}$ & $k \vee v q^{d-k}$ & $\mathrm{V \wedge}$ & $z$ \\
\hline $10 Y \Lambda^{f-j}$ & $19^{a}$ & $|\wedge|^{c o-q}$ & IrVrych-k & $r \Delta \wedge \wedge r^{d-m}$ & $\mathrm{Va}$ & \\
\hline$\| \mu \circ \wedge^{j-1}$ & $q Y^{f-h}$ & $r \mid Q^{\mathrm{kl}}$ & IMTYKf-i & DYMTC-g & Vi。 & \\
\hline $19 \wedge 9^{\mathrm{c}-\mathrm{g}}$ & $V v^{c-e}$ & $r \Lambda^{\mathrm{de}}$ & $1 \circ \circ \wedge \Lambda^{s-u}$ & $r \circ \wedge v^{t-x}$ & Vil & \\
\hline$I V V Q^{b-e}$ & $\Lambda \Delta^{a-c}$ & $r / q^{j-1}$ & $10 \Delta \mid V^{b c}$ & $9.99^{\mathrm{a}-\mathrm{c}}$ & VIr & \\
\hline $\mid r Y^{k} \gamma^{k-m}$ & Q phi & rormn & $\| Y \circ V^{m-s}$ & $r \Delta T^{o-w}$ & VI & \\
\hline $1 \Gamma \wedge \theta^{k-m}$ & $9 r^{f-h}$ & $r_{\circ} 0^{c}$ & $\left.|r q|\right|^{g-j}$ & kqvqf-p & Vr & \\
\hline $1 r \Lambda \lambda^{i-k}$ & $q V^{e-g}$ & $r q \Lambda^{c d}$ & $19 r 91^{a}$ & $\left.\Delta r \&\right|^{c-f}$ & Vr & \\
\hline $1 \wedge 9 Y^{a-c}$ & $\Lambda c^{a-c}$ & سחץ & $190 r r^{b}$ & $011 r^{\mathrm{rch}}$ & $\mathrm{V}^{*}$ & \\
\hline $10 \wedge \mu^{d-i}$ & $99^{\mathrm{ef}}$ & rAYe & $|r v q|^{\text {e-h }}$ & $\psi \mid r \theta^{\mathrm{h}-\mathrm{r}}$ & Vo & $\stackrel{i}{i}$ \\
\hline 1 IrYs & $\Delta \Lambda^{\mathrm{gh}}$ & Fyegh & $1 \circ 4 \xi \Delta^{p-u}$ & $4 \mid Y \Lambda^{\mathrm{h}-\mathrm{s}}$ & V4 & a \\
\hline $1 F V \wedge^{g-k}$ & $q^{r^{f-h}}$ & $r r^{\mathrm{i}-1}$ & $\mid r \Lambda \circ r^{\mathrm{e}}-\mathrm{h}$ & $\Delta r q \Lambda^{c-f}$ & $\mathrm{Vv}$ & $\underline{E_{1}}$ \\
\hline$q \vee \wedge^{\mathrm{n}-\mathrm{p}}$ & $k^{r^{j} \mathrm{jk}}$ & $r \mid q^{j-1}$ & $\mid Y \circ r \Lambda^{d-g}$ & $\Delta \Delta \mu_{0}^{b-d}$ & $\mathrm{V \wedge}$ & $i$ \\
\hline $1.1 \wedge^{\text {no }}$ & $\Delta \varphi^{h i}$ & $r \circ Y^{n}$ & $10 \cdot 01^{b-e}$ & graYab & $\mathrm{Va}$ & \\
\hline $\mid \vee \wedge q^{b-d}$ & $V V^{b-e}$ & TY\&g & $\mid f \wedge \Delta \wedge^{b-e}$ & $9 \Delta \Delta \Delta^{\mathrm{a}}$ & Vi。 & \\
\hline Ylora & $90^{a}$ & $M Q^{b}$ & $11999^{j-q}$ & $40 \cdot 1^{e-0}$ & Vil & \\
\hline $19 \cdot 0^{\mathrm{a}-\mathrm{c}}$ & $\wedge^{\mathrm{a}}$ & $r r^{\mathrm{i}-\mathrm{I}}$ & $10 Y \& V^{b-d}$ & $G \circ Y Y^{\mathrm{a}-\mathrm{c}}$ & VIr & \\
\hline $9 V r^{\mu n-p}$ & $t^{\prime} \mathrm{Yjk}^{\mathrm{jk}}$ & $\backslash \wedge V^{o p}$ & IYY०o & FrVqg-p & VI & \\
\hline$|\wedge| r^{b-d}$ & $\wedge l^{a-d}$ & $r \mu_{0} \mathrm{ij}$ & $\mid r y \circ \Delta^{f-i}$ & $\forall \& Y \wedge^{\mathrm{d}-1}$ & Vr & \\
\hline $1910^{\mathrm{c}-\mathrm{h}}$ & $V V^{b-e}$ & rmphi & $|490|^{b-e}$ & $\Delta r V \Lambda^{c-f}$ & $\mathrm{Vr}$ & \\
\hline $199 r^{\mathrm{ab}}$ & $\wedge \mathrm{v}^{\mathrm{ab}}$ & $r \varphi V^{f}$ & $\mid r \mu q \Lambda^{i-m}$ & $\varphi q \vee \wedge^{d-j}$ & $V^{4}$ & \\
\hline $1 \circ V^{r^{m n}}$ & $r \varepsilon^{\mathrm{ji}}$ & IAV $\mathrm{Vp}^{\mathrm{op}}$ & $|K r y|^{c-f}$ & $r q \circ \circ-u$ & Vo & $\zeta$ \\
\hline $9 \Delta \varphi^{r-t}$ & $r q^{\operatorname{lm}}$ & $r \circ Y^{n}$ & ITVkyh-k & rGY $\lambda^{\mathrm{m}-\mathrm{v}}$ & V4 & 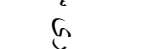 \\
\hline$q r_{0}^{n-q}$ & $r q^{j-1}$ & $199^{\mathrm{no}}$ & ITrKG & FYYYh-q & Vv & $\underline{\varepsilon_{1}}$ \\
\hline$V Q q^{p-r}$ & $\mu^{\mathrm{kl} l}$ & INFoq & $\|\left.\mu \wedge \Delta\right|^{\text {ee-h }}$ & $\Delta \psi \circ \Delta^{c-f}$ & $\mathrm{V \wedge}$ & $\tau$ \\
\hline $11 \mu_{0}^{1-n}$ & $99^{\mathrm{e}-\mathrm{g}}$ & $190^{\mathrm{st}}$ & $\mid K V G \Lambda^{c-e}$ & $\Delta \Delta_{Y} \wedge Y^{-e}$ & $\mathrm{Va}$ & \\
\hline $9 \Delta r^{n-p}$ & $k r^{j \mathrm{jk}}$ & $1 \wedge 9^{0-q}$ & $|f V G|^{\mathrm{c}-\mathrm{e}}$ & $\Delta \circ \Delta \Delta^{d-i}$ & Vi。 & \\
\hline $\mid V \wedge \wedge^{\mathrm{b}-\mathrm{d}}$ & $\Lambda_{0} \mathrm{a}^{\mathrm{d} d}$ & $r \wedge I^{e}$ & $10910^{\mathrm{p}-\mathrm{t}}$ & $M \mid r V^{s-x}$ & Vil & \\
\hline $1090^{\mathrm{d}-\mathrm{i}}$ & $\eta^{\mathrm{d}-\mathrm{f}}$ & $\mid V Y^{q-s}$ & $\mid r \wedge \& q^{\mathrm{e}-\mathrm{h}}$ & $r+4 \wedge g-p$ & VIr & \\
\hline$\Lambda Y^{\mu^{0-r}}$ & $r V^{j-1}$ & $190^{\text {tu }}$ & $1 \circ V \circ \varphi^{<p-u}$ & raYYk-u & VI & \\
\hline$|V Q|^{b-f}$ & $\Lambda^{\mathrm{a}-\mathrm{d}}$ & $r r^{\mathrm{i}-\mathrm{k}}$ & $11 r y \gamma^{k-s}$ & $r \circ 9 Q^{\mathrm{i}-\mathrm{t}}$ & $\mathrm{Vr}$ & \\
\hline $19 \mathrm{rq}^{\mathrm{d}-\mathrm{i}}$ & $V Q^{c-e}$ & TYYil-1 & $\mid r V \circ q^{h-k}$ & 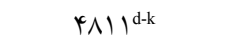 & $\mathrm{Vr}$ & \\
\hline $1 \psi \Delta<q-k$ & $q V^{e-g}$ & Tr & $9 \Delta 9 Y^{u}$ & MTYQq-w & $V^{r}$ & 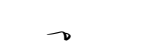 \\
\hline $0 \circ \psi^{s t}$ & $r_{\circ} \mathrm{m}$ & $|V| q-s$ & $M Y Y^{\mathrm{i}-\mathrm{o}}$ & rerql-v & Vo & $\check{5}$ \\
\hline $9999-5$ & $\mu_{0} 1$ & $1 \& \mu_{\text {st }}$ & $9 \wedge \varsigma^{\text {tu }}$ & 1 $199 y$ & $\mathrm{~V}_{4}$ & a \\
\hline$\left.V Q\right|^{p-r}$ & $r Y^{k l}$ & $|V|^{r-t}$ & $1 \circ 091^{p-u}$ & rqrqu-x & Vv & $\underline{\varepsilon}$ \\
\hline$r Q 0^{t}$ & $r_{0} \mathrm{~m}$ & $109^{\text {tu }}$ & $1 \circ \mu_{0} \mathrm{r}-u$ & r49.1-v & V^ & $z^{2}$ \\
\hline$\Lambda I V^{0-r}$ & $k \varepsilon^{i j}$ & $1 \% Q^{v}$ & $11 \circ 91^{\mathrm{n}-\mathrm{t}}$ & $M 19 V^{r-x}$ & $\mathrm{Va}$ & 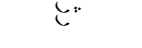 \\
\hline $111^{0-r}$ & $r r^{k l}$ & $100 \mathrm{uv}$ & $|040|^{q-u}$ & r<qVp-w & Vi。 & \\
\hline$|k<|^{g-k}$ & $\Delta \Delta^{\mathrm{hi}}$ & $r T Q^{i-1}$ & $9900^{\circ}$ & $T V \backslash I^{v-y}$ & Vil & \\
\hline$q r 1^{n-q}$ & $r r^{k l}$ & lkquv & $1 \circ \Delta \wedge V^{p-u}$ & $r G \circ V^{w-y}$ & VIr & \\
\hline
\end{tabular}




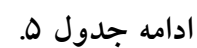

\begin{tabular}{|c|c|c|c|c|c|}
\hline \multirow{2}{*}{ رسيدى فيزيولوزيكى } & \multirow{2}{*}{ 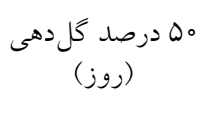 } & \multirow{2}{*}{ 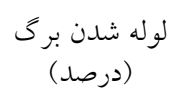 } & \multirow{2}{*}{ شاخص برداشت خوشه } & \multicolumn{2}{|c|}{ تيمار } \\
\hline & & & & زرنوتيِ & رزيم آبيارى \\
\hline $11 q^{a}$ & $109^{\mathrm{a}}$ & $1^{j-n}$ & $q \mu^{\mathrm{e}-\mathrm{g}}$ & VI & \\
\hline $1 r^{\mathrm{c}-\mathrm{f}}$ & $91^{f-h}$ & $\mid r^{\mathrm{j}-\mathrm{n}}$ & $q r^{b-e}$ & Vr & \\
\hline$|Y|^{\mathrm{f}-\mathrm{h}}$ & $9 \wedge^{f-h}$ & $1 r^{\mathrm{j}-1}$ & $q 4^{\mathrm{a}-\mathrm{d}}$ & $\mathrm{Vr}$ & \\
\hline $1 \pi \theta^{b c}$ & $100^{d-f}$ & $10^{\mathrm{n}-\mathrm{s}}$ & $90^{\mathrm{ab}}$ & $V^{k}$ & \\
\hline $1 \mathrm{rq}^{\mathrm{a}}$ & $101^{c-f}$ & $\Lambda^{\mathrm{rs}}$ & $9)^{h-j}$ & Vo & 6 \\
\hline $1 \pi r^{d-f}$ & $9)^{\mathrm{rj}^{j-m}}$ & $q^{q-s}$ & $q_{0} 0^{j-m}$ & Vs & 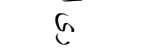 \\
\hline $\mid Y^{c b-d}$ & $101^{c-e}$ & $10^{\mathrm{m}-\mathrm{s}}$ & $9)^{h-j}$ & $\mathrm{Vv}$ & $\Sigma_{-1}$ \\
\hline $1111^{r}$ & $\Lambda r^{v}$ & $10^{\mathrm{n}-\mathrm{s}}$ & $q_{0} 0^{j-1}$ & $\mathrm{V \wedge}$ & $t$ \\
\hline $11 Q^{1-n}$ & $9)^{n-q}$ & ||$^{k_{i j}}$ & $q r^{d-f}$ & $\mathrm{Va}$ & \\
\hline $1 / r^{\text {o-q }}$ & $q_{0} p^{p-s}$ & $1 \mathrm{r}^{\mathrm{j}-\mathrm{m}}$ & $9)^{\mathrm{h}-\mathrm{j}}$ & Vi。 & \\
\hline $1 r \varepsilon^{b}$ & $10 y^{\mathrm{aab}}$ & $1 \kappa^{j-1}$ & $q 4^{\mathrm{a}-\mathrm{d}}$ & Vil & \\
\hline $1 \circ \Lambda^{s}$ & $\wedge q^{p-s}$ & $q^{0-s}$ & $q r^{e-g}$ & VIr & \\
\hline $1 q^{b}$ & $10 \mathrm{r}^{\mathrm{bc}}$ & $10^{\mathrm{m}-\mathrm{s}}$ & $94^{c-f}$ & VI & \\
\hline $119^{\mathrm{ij}}$ & $q \varphi^{h-k}$ & $11^{\mathrm{m}-\mathrm{q}}$ & $q r^{e-g}$ & Vr & \\
\hline $1 r^{\mathrm{c}-\mathrm{e}}$ & $1 \circ Y^{b-d}$ & $q^{p-s}$ & $90^{\mathrm{a}-\mathrm{d}}$ & $\mathrm{Vr}^{\mathrm{r}}$ & \\
\hline $11 \Lambda^{i-k}$ & $90^{\mathrm{i}-1}$ & $\Lambda^{\mathrm{s}}$ & $90^{\mathrm{a}-\mathrm{c}}$ & $V^{*}$ & \\
\hline $11 \mathrm{~N}^{\mathrm{jk}}$ & $90^{\mathrm{i}-1}$ & $\lambda^{\mathrm{rs}}$ & $q r^{e-g}$ & Vo & 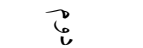 \\
\hline $11 k^{\text {cn-p }}$ & $91^{0-r}$ & $q^{0-s}$ & $9)^{i-k}$ & $\mathrm{~V}_{4}$ & G \\
\hline Irref & $99^{\mathrm{d}-\mathrm{g}}$ & $q^{p-s}$ & $q_{0}^{j-1}$ & $\mathrm{Vv}$ & $\underline{\underline{E}}$ \\
\hline $104 u$ & $\Delta I^{v}$ & $4^{0-s}$ & $\wedge 9^{1-0}$ & $\mathrm{V \wedge}$ & 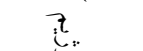 \\
\hline$\| r^{p-r}$ & $\wedge q^{p-s}$ & $10^{\mathrm{m}-\mathrm{s}}$ & $q r^{e-g}$ & $\mathrm{Va}$ & \\
\hline $11 \mathrm{r}^{\mathrm{gr}}$ & $\wedge q^{p-s}$ & $10^{\mathrm{m}-\mathrm{r}}$ & $q r^{g-i}$ & Vi。 & \\
\hline $1 K r^{e f}$ & $99^{e-g}$ & $10^{\mathrm{m}-\mathrm{r}}$ & $q r^{a-d}$ & Vil & \\
\hline $109^{5}$ & $\wedge \varepsilon^{\mathrm{tu}}$ & $q^{p-s}$ & $90^{\mathrm{ab}}$ & VIr & \\
\hline $\mid Y^{\mathrm{fg}}$ & $99^{\mathrm{d}-\mathrm{g}}$ & $11^{\mathrm{j} j-1}$ & $q r^{e-g}$ & $\mathrm{~V}_{1}$ & \\
\hline $11 \mathrm{~V}^{\mathrm{kl}}$ & $94^{k-n}$ & $1 r^{j-n}$ & $90^{\mathrm{a}}$ & Vr & \\
\hline $11 \mathrm{~V}^{\mathrm{kl}}$ & $9)^{\mathrm{rj-m}}$ & $\left.\right|^{j-n}$ & $94^{\mathrm{a}-\mathrm{d}}$ & $\mathrm{Vr}^{\mathrm{r}}$ & \\
\hline $118^{\mathrm{lm}}$ & $q r^{1-0}$ & $11^{\mathrm{k}-\mathrm{o}}$ & $90^{\mathrm{a}-\mathrm{c}}$ & $\mathrm{Vk}$ & \\
\hline$\| \varepsilon^{\mathrm{kl}}$ & $9 \mu^{1-0}$ & $q^{p-s}$ & $9 / /^{h-j}$ & Vo & $\xi$ \\
\hline $10 \wedge^{s}$ & $\Lambda Q^{u}$ & $1 r^{j-n}$ & $\wedge q^{m-0}$ & $\mathrm{~V}_{4}$ & $\hat{G}$ \\
\hline $\mid Y_{0}{ }^{g-i}$ & $9 V^{g-i}$ & $11^{1-p}$ & $9 / /^{h-j}$ & $\mathrm{Vv}$ & $\Sigma_{-1}$ \\
\hline $1 \circ r^{v}$ & $\vee q^{w x}$ & $11^{\mathrm{m}-\mathrm{q}}$ & $\wedge 9 /^{m-0}$ & $\mathrm{V \wedge}$ & $t$ \\
\hline $109^{\mathrm{s}}$ & $\Lambda q^{u}$ & $10^{\mathrm{i}}$ & $q \pi / e^{-g}$ & $\mathrm{Va}$ & c." \\
\hline $1 \circ \Lambda^{\mathrm{s}}$ & $\wedge \Delta^{u}$ & $1 r^{j-n}$ & $9 Y^{g-\mathrm{g}}$ & Vi。 & \\
\hline $1 r_{0}$ hi & $9 V^{g-j}$ & ||$^{\mathrm{ij}}$ & $9 r^{f g}$ & Vil & \\
\hline $109^{t}$ & $\Delta \mu^{v}$ & $\left.\right|^{r^{\mathrm{i}-\mathrm{k}}}$ & $90^{\mathrm{a}-\mathrm{d}}$ & VIr & \\
\hline $\mid Y_{0} g-i$ & $9 V^{g-i}$ & $r_{0}{ }^{h}$ & $\wedge q^{k-n}$ & VI & \\
\hline$\| q^{\mathrm{kl}}$ & $\wedge q^{p-s}$ & r & $90^{\mathrm{ab}}$ & $\mathrm{Vr}_{\mathrm{r}}$ & \\
\hline$\| \mathrm{V}^{\mathrm{kl}}$ & $\wedge \wedge^{q-t}$ & $r \mu g$ & $q 4^{c-f}$ & $\mathrm{Vr}$ & \\
\hline$K r_{0} \mathrm{hi}$ & $\Lambda V^{s-u}$ & Tyg & $90^{\mathrm{a}}$ & $V^{*}$ & \\
\hline $11^{\mathrm{N}^{\mathrm{o}-q}}$ & $\Lambda^{s-u}$ & TYg & $\Lambda^{\circ}$ & Vo & $\stackrel{\check{c}}{0}$ \\
\hline $10 Y^{v}$ & $\Lambda I^{v}$ & $|y|^{\circ}$ & $11^{q}$ & V4 & 4 \\
\hline $11 \mathrm{~km}^{\mathrm{m}-\mathrm{o}}$ & $Q r^{\mathrm{m}-\mathrm{p}}$ & $r \Lambda^{f}$ & $9)^{h-j}$ & $\mathrm{Vv}$ & $\check{c}_{t:}^{n}$ \\
\hline $99^{w}$ & $V q^{x}$ & ryd & $\wedge \mathrm{V}^{\mathrm{p}}$ & V^ & $z^{-1}$ \\
\hline $101^{\text {tuu }}$ & $\Lambda r^{v}$ & $r \Delta^{b}$ & $9 r^{\text {gh }}$ & $\mathrm{Va}$ & 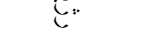 \\
\hline $10 r^{\mathrm{uuv}}$ & $\Lambda 0^{v w}$ & $\mu^{e}$ & $\wedge q^{\mathrm{m}-\mathrm{o}}$ & Vi。 & \\
\hline$\| r^{p-r}$ & $\Lambda \Lambda^{r-t}$ & r & $q r^{\mathrm{fg}}$ & Vil & \\
\hline $100 \mathrm{w}$ & $V V^{x}$ & $9 \Lambda^{\mathrm{a}}$ & $q r^{b-e}$ & VIr & \\
\hline
\end{tabular}


جدول 9. ضر ايب همبستخى بين عملكرد دانه و صفات مورد بررسى زنوتيبٍهاى برنج

\begin{tabular}{|c|c|c|c|c|c|c|c|c|c|}
\hline 9 & $\wedge$ & V & 9 & 0 & $\varphi$ & $\mu$ & $r$ & 1 & \\
\hline & & & & & & & & 1 & 1 - عملكرد دانه \\
\hline & & & & & & & 1 & $\circ / 9 V r^{* *}$ & r- ماده خشى \\
\hline & & & & & & 1 & $\circ / \mu Y V^{* *}$ & $\circ /\left(Q Y^{* *}\right.$ & "r- تعداد ينجه \\
\hline & & & & & 1 & $\circ / 910^{* *}$ & $\circ / \Gamma 19^{* *}$ & $\circ /(\Upsilon 9)^{* *}$ & با بـ ميزان رسيدكى \\
\hline & & & & 1 & $\circ / 944^{* *}$ & $0 /\left.99\right|^{* *}$ & $\circ / Y \Delta Y^{* *}$ & $\circ / Y Y Y^{* *}$ & ه- درجه رسيدگى \\
\hline & & & 1 & $\circ / \Delta \wedge \wedge^{* *}$ & $\circ / 900^{* *}$ & 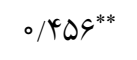 & $\circ / Y \& Y^{* *}$ & $\circ / \mathrm{V} \varphi^{* *}$ & צ- شاخص برداشت \\
\hline & & 1 & $-0 / Y Y Q^{* *}$ & $-\circ / \mathcal{F r} \Lambda^{* *}$ & $-\circ / \mathcal{K Y} \Lambda^{* *}$ & $-0 / 01 V^{* *}$ & $-0 / T 90^{* *}$ & $-0 / 4 \& r^{* *}$ & V- لوله شدن برى \\
\hline & 1 & $-\circ / \Delta \mu_{\circ}^{* * *}$ & $\circ /\left.\Gamma \Delta\right|^{* *}$ & $\circ / 4 V I^{* *}$ & $\circ / \mathcal{K} V^{* *}$ & $\circ / \Delta Y \wedge^{* *}$ &.$/|4|^{*}$ & -.०/०هr & 1- •ه درصد گل مهى \\
\hline 1 & $\circ / 9 \circ \mu^{* * *}$ & $-\circ / 0 \mid Y^{* *}$ & $\circ / 4 \circ \circ * *$ & $\circ / 0 \circ 0^{* *}$ & $\circ / \mathbb{F} \vee r^{* *}$ & $\circ / \Delta 9 V^{* *}$ & $\circ / 0 \Delta 9$ & $-0 / 090$ & 9- رسيدكى فيزيولوزيكى \\
\hline
\end{tabular}

تعداد ينجهه نيـز مطـابق بحــث بيشـين داراى همبسـتخى مثبـت و

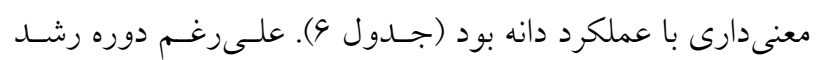
رويشى كوتاهتر در رزيم آبيارى هفت روزه، نتايج حاصل مربـوط به خشكى و فقدان آب لازم جهت تحريك ينجسهزنسى بيشـتر بـا توجه به سازكارى بالاى زنوتيڤهاى مزبور در رزيـم آبيـارى دوم با تناوب آبيـارى سـه روزه بـود. نتـايج بـهدسـت آمـله بـا سـاير

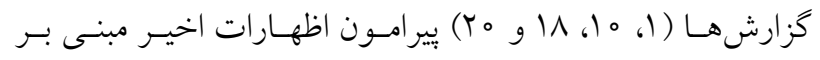
كاهش تعداد ينجه در رزيمهاى آبيـارى بـا فواصـل آبيـارى زيـاد

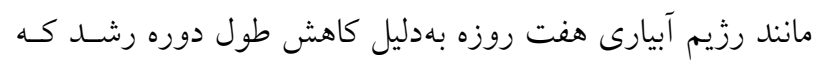

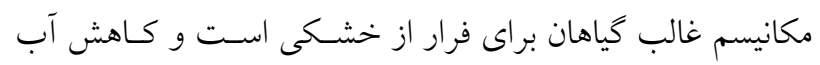
لازم جهت تحريك بنجه بيشتر مطابقت دارد.

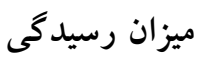
در اين يزوهش مشخص شـد ميـزان رسـيدگى در ميـان اتــرات

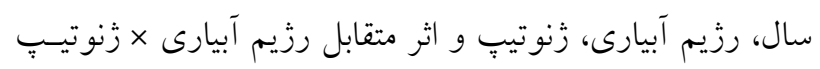
در سطح يك درصد معنى دار است درحالى كـه در سـاير مـوارد،

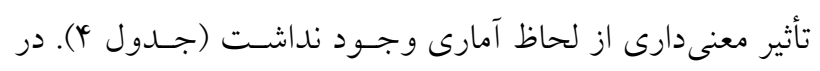

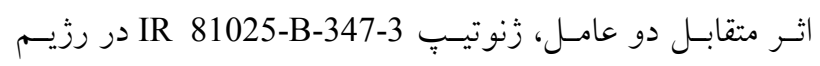

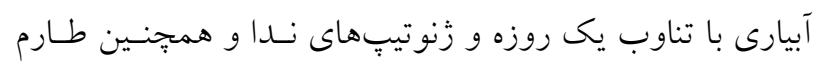
در رزيم آبيارى با تناوب سه روزه، بيشترين ميسزان رسـيدگى را لـا
در شرايط آبيارى يك روزه (غرقاب) بهدليل افزايش شستشـوى مواد غذايى و خارج از دسترس كردن آنها توسط كياه همجنسين

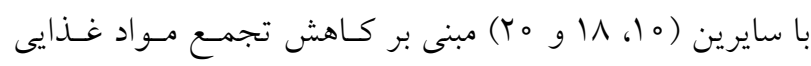
جهت افزايش ماده خشك گياه بهدليل كاهش دوره رشد گياه در شرايط افزايش خشكى مطابق آنجهه در رزيم آبيـارى جهـارم بـا تناوب آبيارى هفت روزه رخ داد، كاملاً همخوانى دارد.

تعداد ينجه در مترمربع

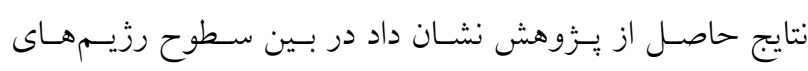

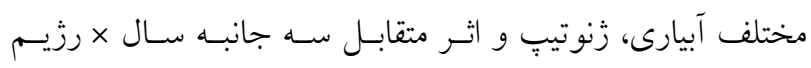

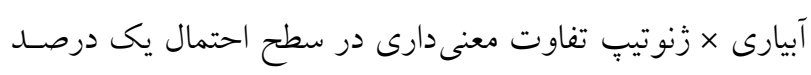
وجود دارد ولى در سـاير سـطوح اخـتلاف معنسى دارى از لحـاظ آمارى مشاهده نشد (جدول f). مقايسه ميانخين نشان داد بـه غيسر از زنوتيِّ با مقاومت بايين IR 80508-B-194-4-B كـهـ بيشـترين ينجه را در رزيم آبيارى يك روزه دارا بـود سـاير زنوتيـٍِهــا در رزيم آبيارى دوم با تناوب آبيارى سه روزه از تعداد ينجه بيشترين

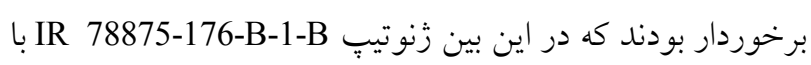
متوسط هم/آس تعداد يُنجه در مترمربـع، بيشـترين تعـداد رادر اين رزيم آبيـارى داشـت. كمتـرين تعـداد آن نيـز هماننـد ديخــ

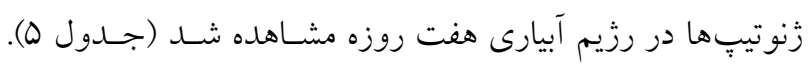


شاخص برداشت خوشه در اين يزوهش مشخص شد شاخص برداشت خوشه در بين سال،

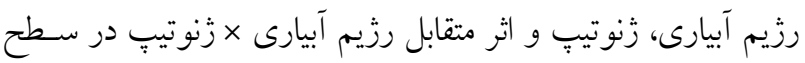
يك درصد معنى دار است (جدول \&). اثر متقابـل زنوتيـٍ × رزيــم

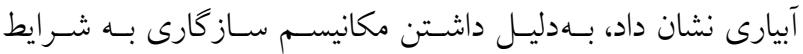
كاهش ميـزان يـا دور آبيـارى، زنوتيـب IR 78908-193-B-3-B

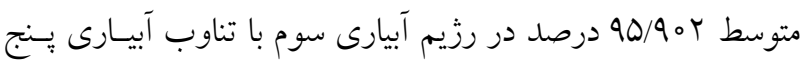

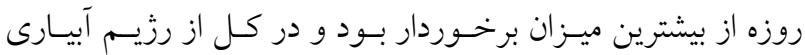

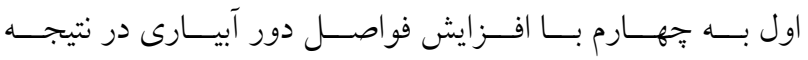

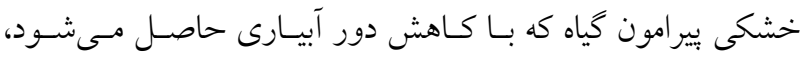

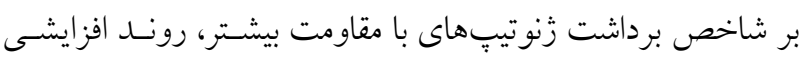

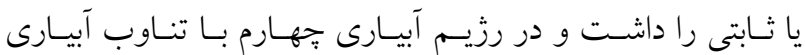

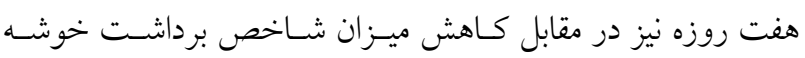
از خود، بيشترين مقاومت و كمترين كاهش را داشـتند يـا بـه بيـانى

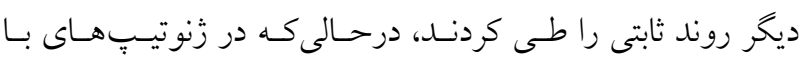

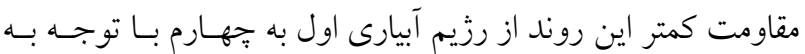

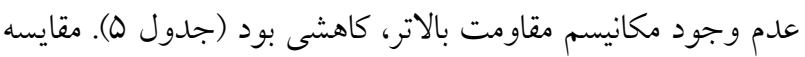

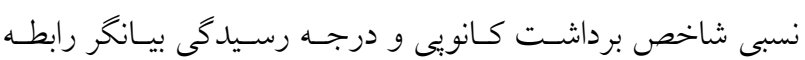

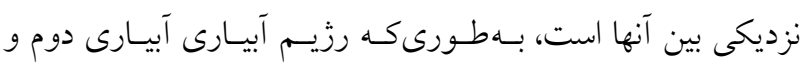

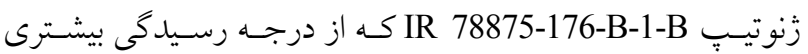
برخوردار بودنــ، مقــدار بيشترى از شـاخص برداشـت خوشـه را داشتند. بر اين اساس علاوهبر توليد خوشـهــاى سـنخين، افزايش سهم نسبى ماده خشك دانه خوشه از كل نيـز بسـيار مهـم اسـت و

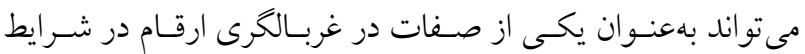
خشكى و تنش بهكار گرفته شود. اين عوامـل همكسى مسى توانــ از دلايل اصلى همبستخى مثت و معنى دار اين صفت با عملكـــد دانـه

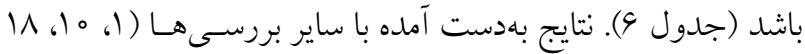

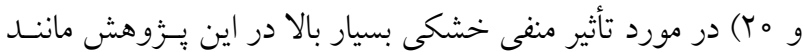

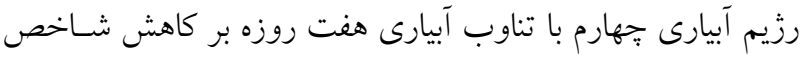

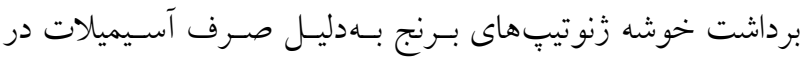

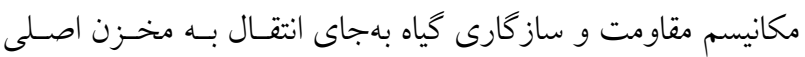
كياه همخوانى دارد.
IR 79971-B-202-2-4 دارا بودند و كمترين ميـزان رازنوتيـ"

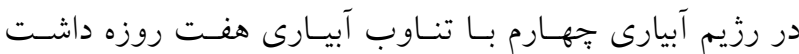

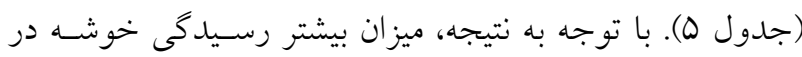

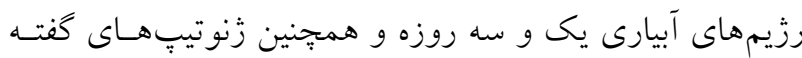

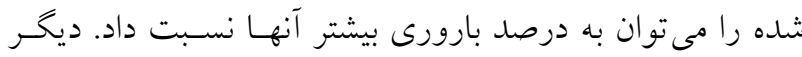

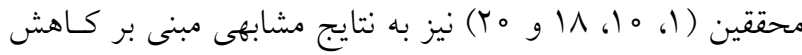

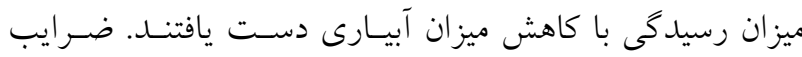

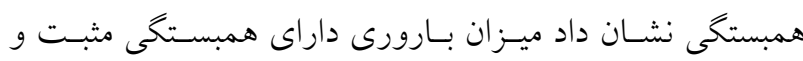
معنى دارى با عملكرد دانه بود كه مى تواند بهدليل افزايش تعـداد

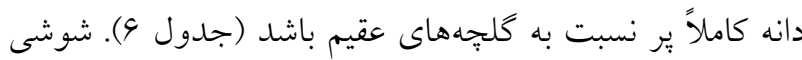

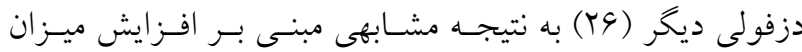
رسيدگى با افزايش رطوبت ييرامون كياه مانند رزيمهاى آبيـارى يكى و سه روزه بهدليل افـزايش تعــاد دانسهــاى بـارور دسـت

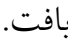

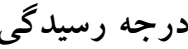

در اين بزوهش مشخص شد كه درجه رسيد ردى در ميـان سـال،

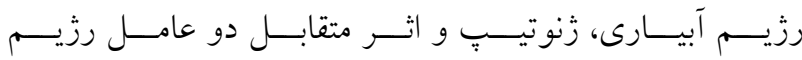

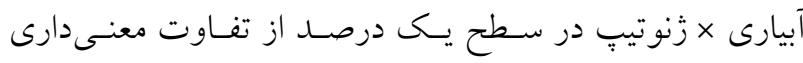

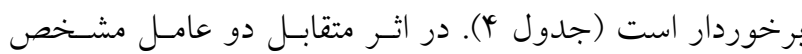
شد، زنوتيٍ ندا كه از بيشترين ميـزان بـارورى برخـوردار بـود،

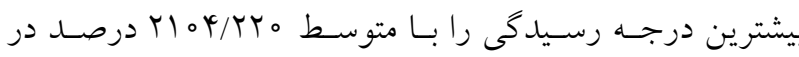

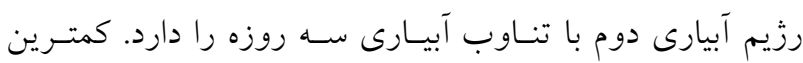

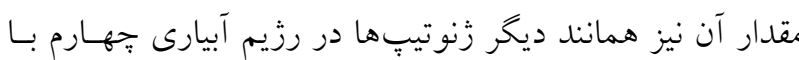

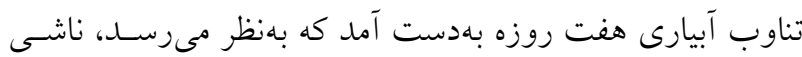

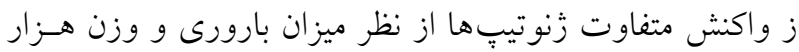

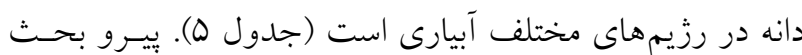

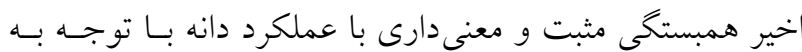

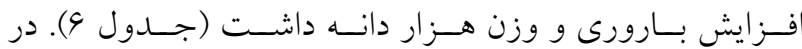
خصوص اظهارات اخير نتايج بهدست آمده با بررسى هاى مشابه

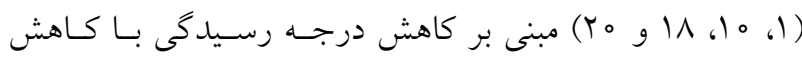
ميزان آبيارى پِاى بوته در يك راستا قرار داشت. 


\section{تعداد روز تا •ه درصد گل دهى}

در اين بررسى مشخص شد كه بين سال، رزيم آبيارى، زنوتيـ"

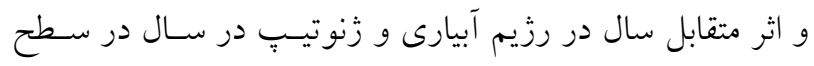

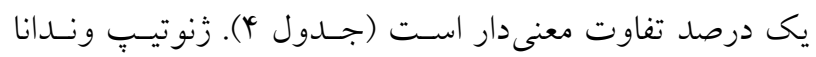

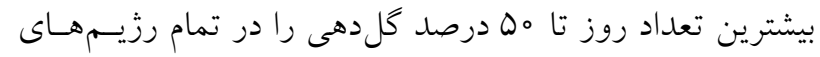

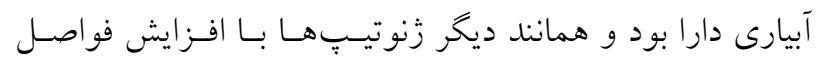

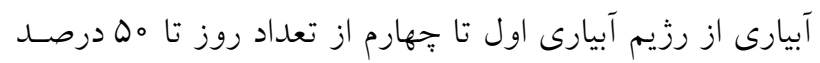

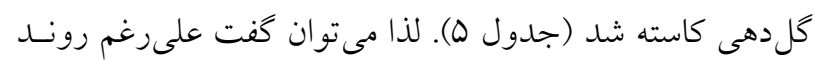

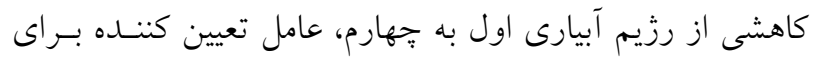

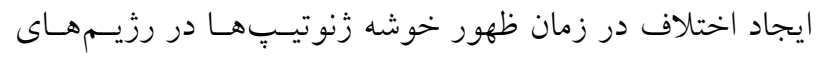

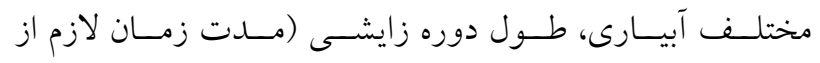

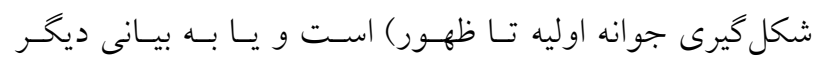

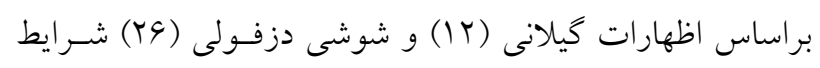

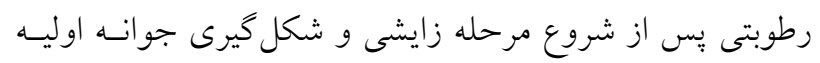

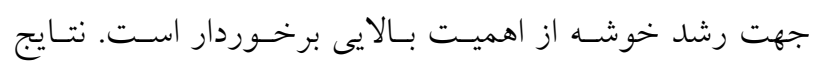

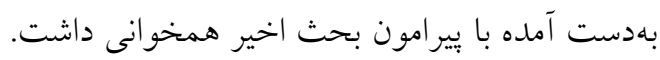

\section{تعداد روز تا رسيدگى فيزيولوزيك} طول دوره رشد يك زنوتيب بـهدليـل اثـرات متقابـل بـين ميـزان

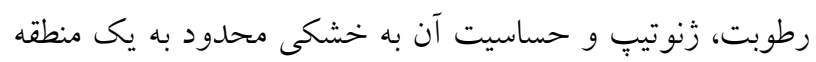

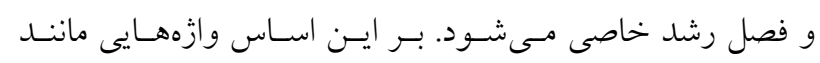

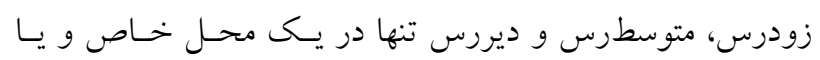
ميزان آبيارى مشخص معنا بيدا مى كند كه البته در اقليمهاى مشابه

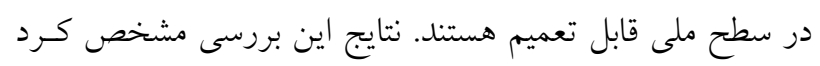

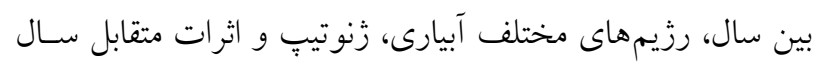

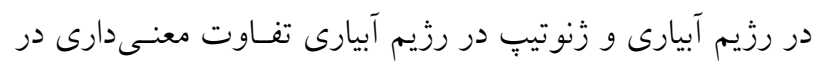

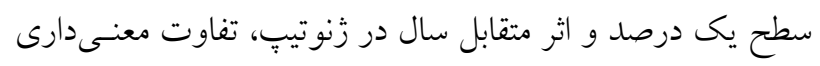
در سطح ينج درصد وجود داشت، ولى همانند صـفت تعـداد روز تا مه درصد كل دهى در ساير سطوح تفاوت معنى دارى از لحساظ

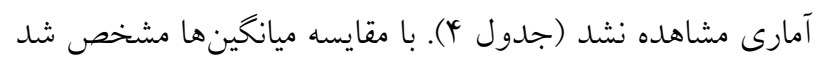

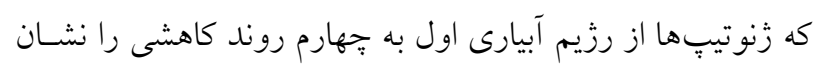

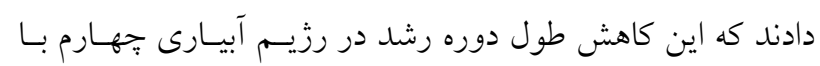

ميزان لوله شدن برى

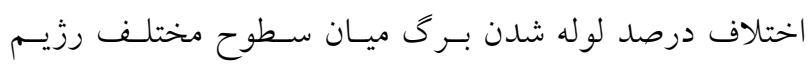

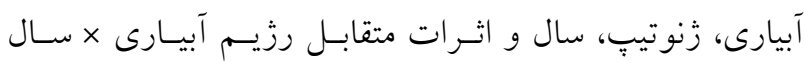

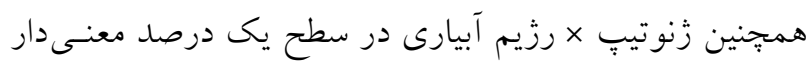

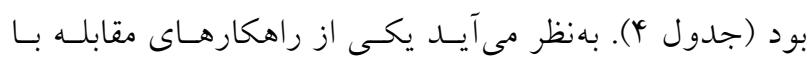

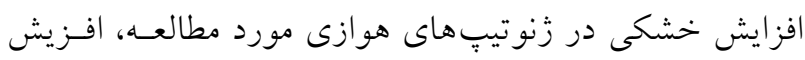

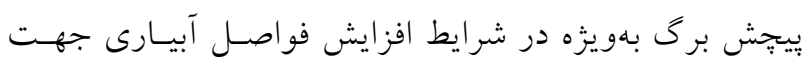

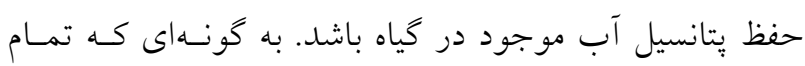

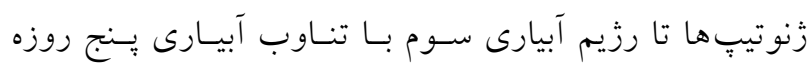

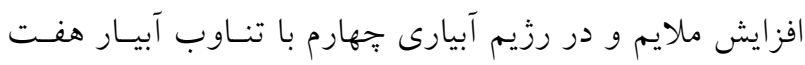

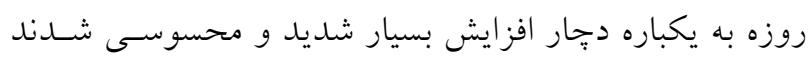

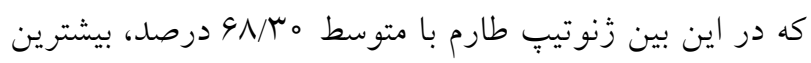

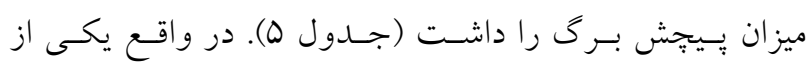

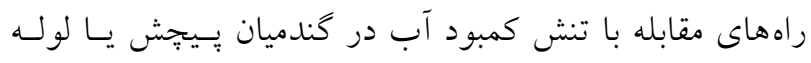

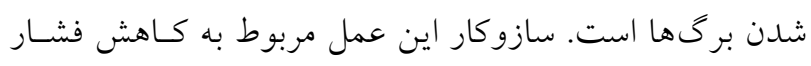

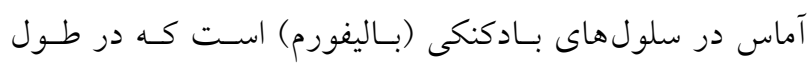

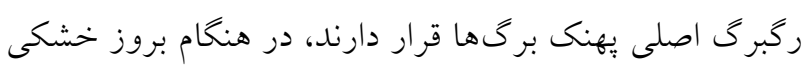

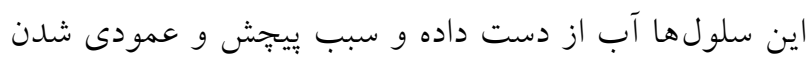

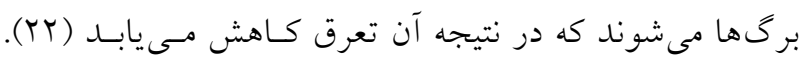

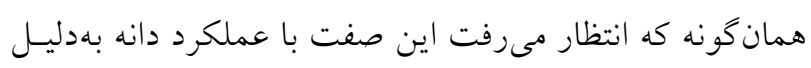

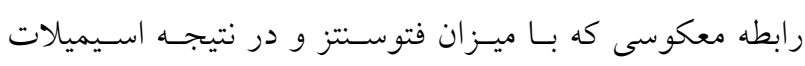

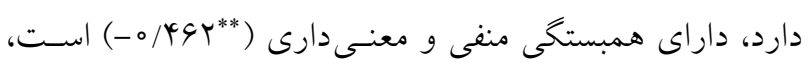

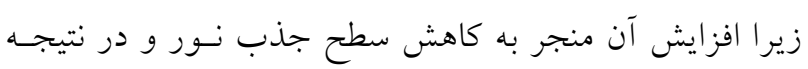

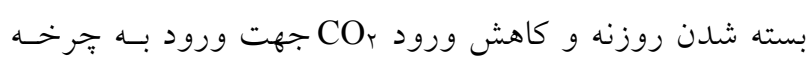

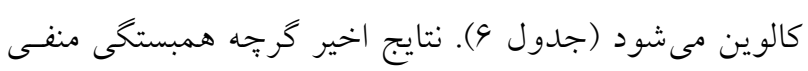

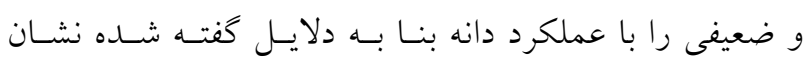

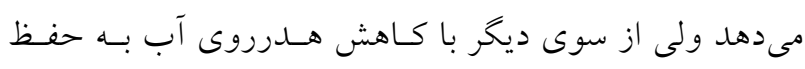

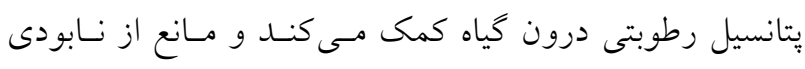

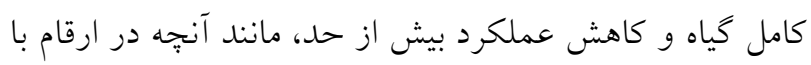
مقاومت به خشكى يايين روى مىدهد، مى شود. يافته هاى ايسن

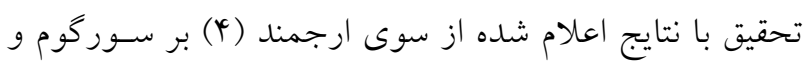
بهنامفر (9) مطابقت داشت. باتج 


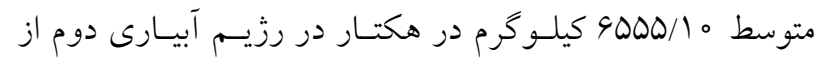

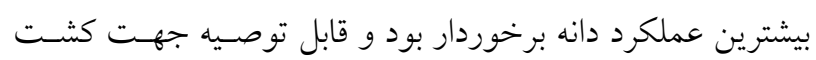
در شرايط مشابه است. در رزيمهاى آبيارى با فواصل يك، يـنج و هفت روزه نيز بهترتيب زنوتيِّهـاى طـارم، و 81429-B-31 بيشترين عملكرد دانه را داشتند. همجنــين در اين تحقيق از برخى صفات فيزيولوزيكى نظير درصد بيّجش برى جهت نشان دادن تأثير تيمارهاى مورد مطالعه بر رشد و نمو گيـاه برنج استفاده شد و مشاهده شد كه تيمارهاى مورد بررسى بهويـزّه خشكى تأثير قابل ملاحظهاى بـر صـفات مـذكور داشـتند. نتـايج بــهدسـت آمــده حــاكى از تغييـرات شــديد فيزيولــوزيكى در

$$
\text { زنوتيِهاى برنج در اثر خشكى بود. }
$$

زنوتيِّهاى با مقاومت بيشتر به لحساظ دارا بـودن مكانيسـم

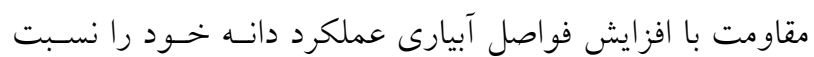
به زنوتيتهاى با مقاومت كمتر بهتر حفظ كردند ولى در شرايط آبيارى روزانه، بهدليل افزايش انرزى مقاومـت نسـبت بـه ديخــ

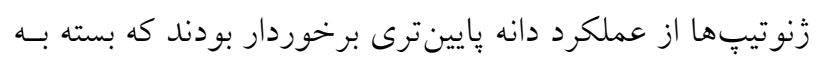
شرايط متفاوت رطوبتى مىتوان از آنها استفاده كرد. بهطـوركلى، خـزارشهـاى موجـود حـاكى از آن اسـت كـه بسيارى از فرآيندهاى فيزيولوزيكى و حياتى در كياهان حسـاس به كمبود آب نظير برنج، يِيش از مشاهده هر كونه علائم كم آبى، دجار اختلال مسى شـوند. نتـايج نشـان داد كـه شـناخت اتــرات تنشهاى محيطى بر برنج اخر بر شناخت روابـط گيـاه و محسيط بير امون و براسـاس صـفات مورفوفيزيولـوزيكى (كليـه صـفات مورد بررسى) استوار شود، كمك شايان توجهى به تعيسين مسـير برنامههاى بـزراعى براى دستيابى به عملكرد بالا خو اهد كرد.
تناوب آبيارى هفـت روزه، مسىتوانـد مكانيسـمى جهــت فــار از خشكى در مرحله زايشى باشد و مىتواند از عوامل اصلى كـاهش عملكرد دانه در اين رزيم آبيارى باشد. در واقع كليه زنوتيـٍِهـا با حفظ برترى زنوتيّ ونـدانا از لحـاظ بـالا بـودن طـول دوره رسيدكى فيزيولوزيكى در تمام رزيسمهــــ آبيـارى، ايسن رونـــ

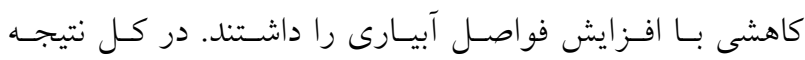
بهدست آمله مى توانـــ مربـوط بـهـ اثـر مقــادير متفــاوت ميـزان رطوبت ياى بوته در هريك از مراحل نموى و كل دوره رشـــ و نيز نقش خشكى و سهم نسبى آن از طريق تحريك رشد زايشى

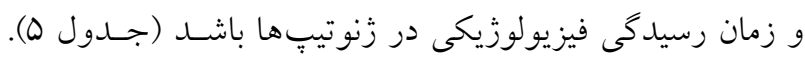
كيلانى (I T) و شوشى دزفولى (Y) نيز كزارشات مشابهى مبنى بر كاهش طول دوره رسيدگى فيزيولوزيكى بهعنوان عامل اصلى مقابله با تنش يا شرايط ناساز گار بيان داشتند.

\section{نتيجه كيرى}

نتايج اين بررسى مشخص كـرد رزيسم آبيـارى سـه روزه بـهلحـاظ

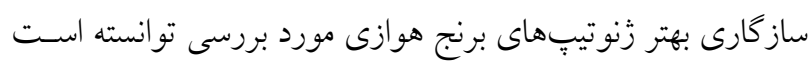

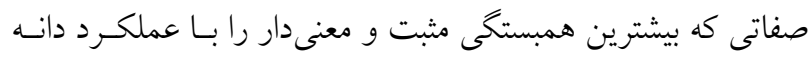
دارا بودند، افزايش و صفاتى كه همبسـتخى منفـى دارنـــ را كـاهش دهد و در نهايت سبب افزايش عملكرد كليه زنوتيبٍهـا بـه غيــر از زَنوتيِّ با مقاومت كم به خشـكى IR 80508-B-194-4-B بـهدليـل مكانيسم مقاومت كمتر در نتيجه افزايش تخصسيص آسـيميلات بـهـ

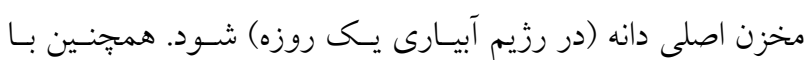

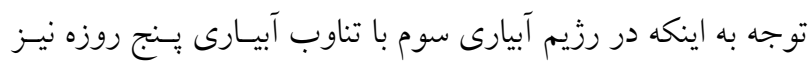
عملكرد قابل قبول و بيشتر از يكى روزه داشتند، مسىتـوان از ايـن

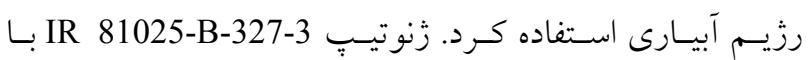

\section{منابع مورد استفاده}

1. Abdola, A. A. and M. J. Zarea. 2015. Effect of Mycorrhiza and Root Endophytic Fungi under Flooded and SemiFlooded Conditions on Grain Yield and Yield Components of Rice. Crop Production 8(1): 223-230.

2. Akbari, S., M. Kafi and S. Rezvan Beidokhti. 2016. The effect of drought stress on Yield, yield components and anti-oxidant of two garlic (Allium sativum L.) ecotypes with different planting densities. Journal of Agroecology 8(1): 95-106.

3. Allah-Gholipour, M. 2007. Study of correlation between some important agronomy and grain yield in rice using path analysis. MSc. Thesis. Tehran Agricultural University. Karaj. Iran. (In Farsi). 
4. Arjmand, A. 1998. Adjusted analysis of sorghum water requirement in the presence of potassium ions in southern Khuzestan climatic conditions. MSc. Thesis. Islamic Azad University, Dezful Branch.

5. Arvin, P. and J. Vafabakhsh. 2016. Study of drought and plant growth promoting rhizobacteria (PGPR) on radiation use efficiency and dry matter partitioning into pod in different cultivars of Brassica oilseed rape. Journal of Agroecology 8(1): 134-152.

6. Bhnamfar, K. 1997. The effect of potassium fertilizer on resistance to drought stress and water use efficiency in corn in Khuzestan weather conditions. MSc. Thesis. Islamic Azad University of Ahvaz.

7. Carmelita, M., R. Albertoa, R. Wassmanna, T. Hiranob, A. Miyatac, R. Hatanob, A. Kumara, A. Padrea and M. Amante. 2011. Comparisons of energy balance and evapotranspiration between flooded and aerobic rice fields in the Philippines. Agricultural Water Management (98): 1417-1430.

8. Chowdhury, M. D. R., V. Kumar, A. Sattar and K. Brahmachari. 2014. Studies on the water use efficiency and nutrient uptake by rice under system of intensification. Bioscan 9(1): 85-88.

9. Dong, N. M., K. K. Brandt, J. Sorensen, N. N. Hung, C. V. Hach, P. S. Tan and T. Dalsgaard. 2012. Effects of alternating wetting and drying versus continuous flooding on fertilizer nitrogen fate in rice fields in the Mekong Delta, Vietnam. Soil Biology of Biochemical 47: 166-174.

10. Durand, M., B. Porcheron, N. Hennion, L. Maurousset, R. Lemoine and N. pourtau. 2016. Water Deficit Enhances C Export to the Roots in Arabidopsis thaliana Plants with Contribution of Sucrose Transporters in Both Shoot and Roots. Plant Physiology 170(1): 1460-1479.

11. Ghasemi-Nasr, M., F. Karandish, A. D. Naft-Chali and A. Mokhtasa-Bigdali. 2016. Effect of Two Periods of MidSeason Drainage on Growth Parameters of Two Rice Varieties. Iranian Journal of Water Research in Agriculture 29 (4): 419-431.

12. Gilani, A. 2010. Determination of tolerance mechanisms and physiological effect of heat stress on rice cultivars in Khouzestan. PhD. Thesis. Agriculture and Natural Resources University of Ramin, Ahwaz, Iran.

13. Ghosh, B. and N. Chakma. 2015. Impacts of rice intensification system on two C. D. blocks of Barddhaman district. West Bengal of Current Science 109(2): 342-346.

14. Jagadish, S. V. K., P. Q. Craufurd and T. R. wheeter. 2007. High temperature stress and spikelet fertility in ricen (Oryza Sativa. L.). Journal of Experimental Botany 58(7): 1627-1635..

15. Horie, T., T. Matsui, H. Nakagawa and K. Omasa. 1996. Effect of elevated $\mathrm{CO}_{2}$ and global climate change on rice yield in Japan. In: K. Omasa, K. Kai, H. Taoda, Z. Uchisima and M. Yoshino (Eds.) Climate Change and Plants in East AsiaTokyo 39-56.

16. Limouchi, K., S. A. Siadat and A. Gilani. 2014. Effect of planting date on yegetative growth and yield of three rice cultivares in north regions of Khuzestan. Agronomic Research in Semi Desert Regions 11(1): 51-63.

17. Matsushima, S., T. Tanaka and T. Shini. 1964. Analysis of development factors detemining yield and yield prediction and culture improvement in low land rice. Crop Science Society of Japan 33: 44-48.

18. Mohd-Zain, N. A. and M. Razi-Ismail. 2016. Effects of potassium rates and types on growth, leaf gas exchange andbiochemical changes in rice (Oryza sativa) planted under cyclic water stress. Agricultural Water Management 164(1): 83-90.

19. Mosavy, S. A., M. R. Khaledian, A. Ashrafzadeh and P. Shahinrokhsar. 2016. Effects of limited irrigation on yield and water productivity increasing of three soybean genotypes in Rasht region. Iranaian Journal of Water Research in Agriculture 29(4): 433-446.

20. Pandey, A., A. Kumar, D. S. Pandey and P. D. Thongbam. 2014. Rice quality under water stress. Indian Journal of Advances in Plant Research 1(2): 23-26

21. Park, G. H., J. H. Kim and K. M. Kim. 2014. QTL analysis of yield components in rice using a cheongcheong/nagdong doubled haploid genetic map. American Journal of Plant Sciences 5: 1174-1180.

22. Sakynazhad, T. 2003. Effects of water stress on the uptake of nitrogen, phosphorus, potassium and sodium in different periods of growth, according to the morphological characteristics and Physiology corn in Ahvaz weather conditions. PhD. Thesis, Islamic Azad University, Science and Research Branch of Ahvaz.

23. Saneoka, H. S. and W. Agata. 1996. Cultivar differences in dry matter production and leaf water relations in waterstressed maize. Grassland Science 41(4): 294-301.

24. Sedaghat, N., H. Pirdashti, R. Asadi and Y. Mousavi-Taghani. 2015. Effect of different irrigation methods on rice water productivity. Journal of Water Research in Agriculture 28(1): 1-9.

25. Shanmugasundaram, B. 2015. Adoption of system of rice intensification under farmer participatory action research programme (FPARP). Indian Research Journal of Extension Education 15(1): 114-117.

26. Shoushi-Dezfuli, A. 1998. Estimation effect genes and correlation between some quantitative and qualitative of rice cultivars. MSc. Thesis. Guilan Agricultural University. Guilan. Iran. (In Farsi).

27. Srayloo, M., H. Sabouri and A. R. Dadras. 2015. Assessing genetic diversity of rice genotypes using microsatellite markers and their relationship with morphological characteristics of seedling stage under non- and drought-stress 
conditions. Cereal Research Communications 5(1): 1-15.

28. Tan, X., D. Shao, H. Liu, F. Yang, C. Xiao and H. Yang. 2013. Effects of alternate wetting and drying irrigation on percolation and nitrogen leaching in paddy fields. Paddy Water Environment 11: 1-15.

29. Tarlera, S., M. C. Capurro, P. Irisarri, A. F. Scavino, G. Cantou and C. Roel. 2015. Yield-scaled global warming potential of two irrigation management systems in a highly productive rice system. Scientia Agricola 73(1): 43-50.

30. Tavala, R., A. Aalami, H. Sabouri and A. sabouri. 2015. Evaluation of haplotype and allelic diversity of SSR markers linked to major effect QTL on chromosome 9 controlling drought tolerance in rice. Cereal Research 5(1): 107-119.

31. Tuong, T. P., B. A. M. Bouman and M. Mortimer. 2005. More rice, less waterintegrated approaches for increasing water productivity in irrigated rice-based systems in Asia. Plant Production Science 8: 231-41.

32. Tuyen, D. D. and D. T. Prasad. 2008. Evaluating difference of yield trait among rice genotypes (Oryza sativa L.) under low moisture condition using candidate gene markers. Journal of Omonrice 16: 24-33.

33. Uphoff, N., A. Kassam and A. Thakur. 2013. Challenges of increasing water saving and water productivity in the rice sector: introduction to the system of rice intensification (SRI) and this issue. Taiwan Journal of Water Conserv 61: 1-13.

34. Yoshida, S. 1973. Effects of temperature on growth of the rice plant in a controlled environment. Soil Science and Plant Nutrition 19: 299-310.

35. Yoshida, S. 1978. Tropical climate and its influence on rice IRRI - Discussion papers series. pp. 20.

36. Yoshida, S. 1981. Fundamentals of Rice Crop Science. International Rice Research Institue. Manila, Philippines. 


\title{
Effect of Different Irrigation Regimes on the Vegetative and Reproductive Traits of Aerobic Rice Genotypes in the North of Khuzestan
}

\author{
K. Limouchi ${ }^{*}$, F. Fateminick ${ }^{2}$, A. Siyadat ${ }^{3}$, M. Yarnia ${ }^{4}$, A. Guilani ${ }^{5}$ and V. Rashidi ${ }^{6}$
}

(Received: March 2-2017; Accepted: January 27-2018)

\begin{abstract}
This research was designed and implemented to determine the effect of different irrigation regimes on the grain yield, dry matter, tiller number per unit area, degree of maturity, panicle harvest index, percentage of leaf rolling, day to $50 \%$ flowering, and the physiological maturity of rice genotypes, using a split plot randomized complete block design in two years (2014 and 2015). Four irrigation regimes (every 1, 3, 5 and 7 days of irrigation) were assigned to the main plots and 12 rice genotypes were in the subplots with three replications. The results showed that irrigation regimes, genotypes and interactive effects of these two factors had a significant impact on all measured traits at the $1 \%$ probability level. All genotypes tended to produce the most grain yield in the second irrigation regime (the three-day irrigation interval); genotype IR $81025-\mathrm{B}-327-3$, with $6555.10 \mathrm{~kg} \mathrm{ha}^{-1}$ of grain yield, out-performed the remaining genotypes in this level of irrigation regime. Also, the second irrigation regime (the three-day irrigation interval) had the highest amount of dry matter, tiller number, degree of maturity, and panicle harvest index. Considering the positive and significant correlation between these traits and grain yield, their increase could be regarded as one of major reasons for the increase in the grain yield at the second irrigation regime (the three-day irrigation interval). The degree of maturity with day to $50 \%$ flowering and physiological maturity were decreased with increasing irrigation intervals; the latter modifications could be regarded as a defense mechanism to avoid drought.
\end{abstract}

Keywords: Irrigation Intervals, Yield, Biological, Cluster, Maturity

1. PhD. Agronomy, Young Researchers and Elite Club, Dezful Branch, Islamic Azad University, Dezful, Iran.

2. Trainer, Department of Agriculture, Payame noor University, Iran.

3. Professor, Department of Agronomy, University of Agricultural and Natural Resources of Ramin, Ahwaz, Iran.

4, 6. Professor and Assistant Professor, Respectively, Department of Agronomy and Plant Breeding, Faculty of Agriculture, Tabriz Branch, Islamic Azad University, Tabriz, Iran.

5. Assistant Professor of Seed and Plant Improvement Research Department, Khuzestan Agricultural and Natural Resources Research Center, AREEO, Ahvaz, Iran.

*: Corresponding Author, Email: Kavehlimouchi@yahoo.com 